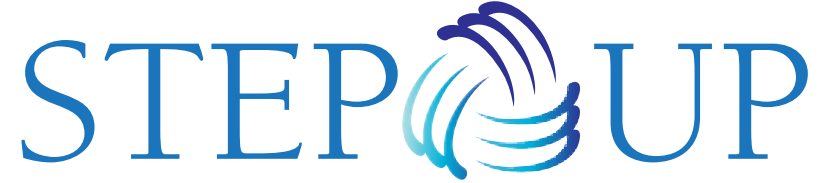

STRENGTHENING EVIDENCE FOR PROGRAMMING ON UNINTENDED
GHANA

RESEARCH REPORT

FEBRUARY 2013

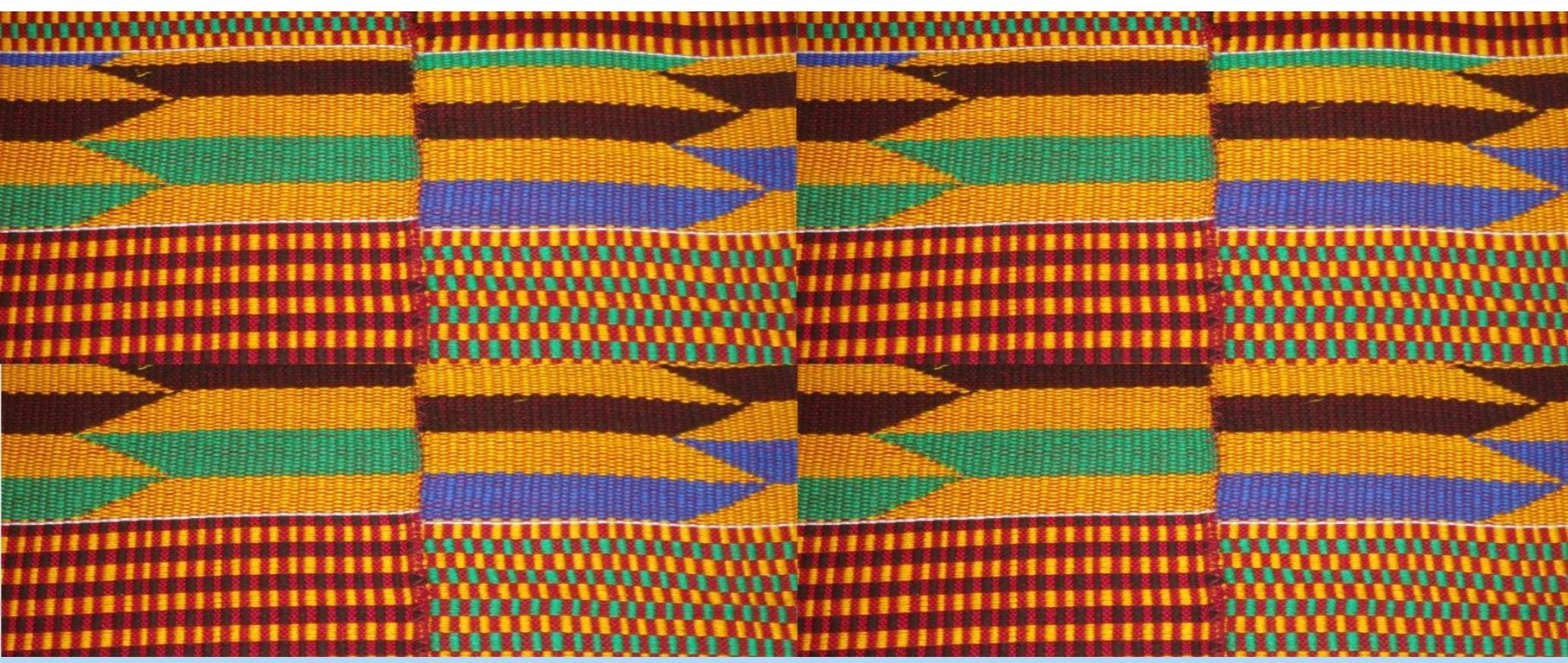

\title{
Insights into Unmet Need in Ghana
}

KAZUYO MACHIYAMA AND JOHN CLELAND

LONDON SCHOOL of HYGIENE \&TROPICAL

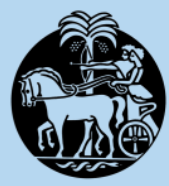




\section{Insights into Unmet Need in Ghana}

KAZUYO MACHIYAMA AND JOHN CLELAND

London School of Hygiene \& Tropical Medicine

STEP UP RESEARCH REPORT

FEBRUARY 2013 
The STEP UP (Strengthening Evidence for Programming on Unintended Pregnancy) Research Programme Consortium generates policy-relevant research to promote an evidence-based approach for improving access to family planning and safe abortion. STEP UP focuses its activities in five countries: Bangladesh, Ghana, India, Kenya, and Senegal. STEP UP is coordinated by the Population Council in partnership with the African Population and Health Research Center; icddr,b; the London School of Hygiene and Tropical Medicine; Marie Stopes International; and Partners in Population and Development. STEP UP is funded by UK aid from the UK Government. www.stepup.popcouncil.org

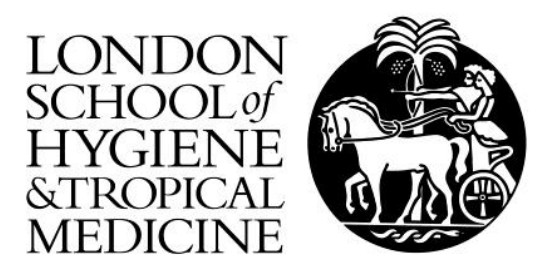

The London School of Hygiene \& Tropical Medicine is a world-leading centre for research and postgraduate education in public and global health. Our mission is to improve health and health equity in the UK and worldwide; working in partnership to achieve excellence in public and global health research, education and translation of knowledge into policy and practice. www.lshtm.ac.uk

\section{(2) Population Council}

The Population Council confronts critical health and development issues-from stopping the spread of HIV to improving reproductive health and ensuring that young people lead full and productive lives. Through biomedical, social science, and public health research in 50 countries, we work with our partners to deliver solutions that lead to more effective policies, programs, and technologies that improve lives around the world. Established in 1952 and headquartered in New York, the Council is a nongovernmental, nonprofit organization governed by an international board of trustees. www.popcouncil.org

Suggested citation: Machiyama, K. and Cleland J. 2013. "Insights into Unmet Need in Ghana," STEP UP Research Report. London: London School of Hygiene \& Tropical Medicine.

C 2013 London School of Hygiene \& Tropical Medicine

Please address any inquiries about STEP UP to the RPC co-directors:

Dr. Harriet Birungi, hbirungi@popcouncil.org

Dr. lan Askew, iaskew@popcouncil.org

Funded by

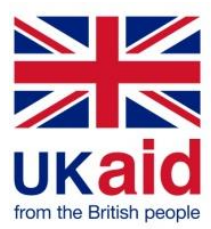




\section{Contents}

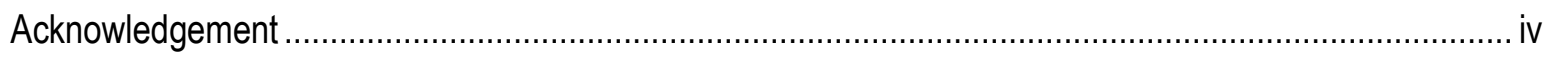

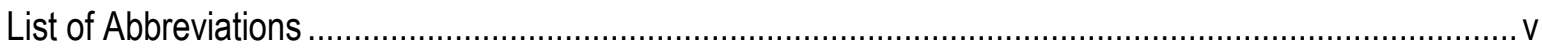

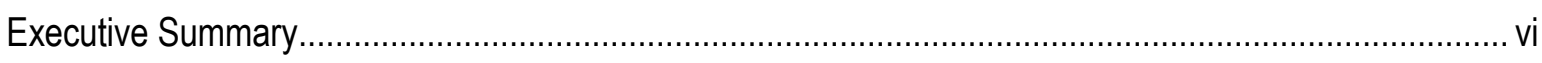

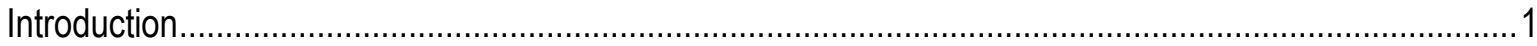

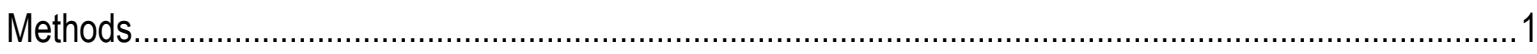

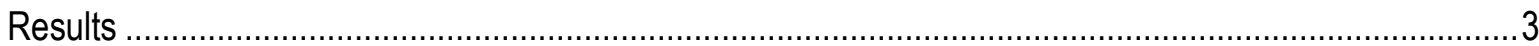

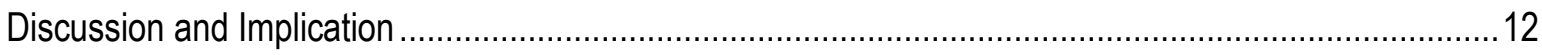

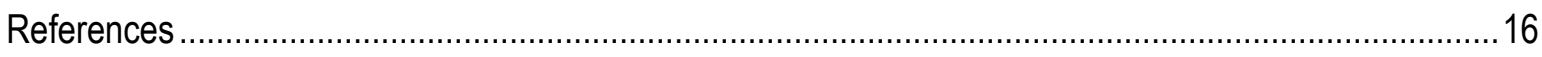

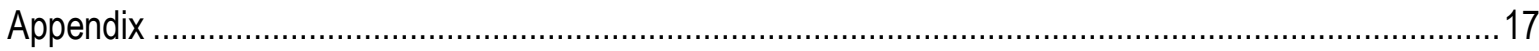




\section{Acknowledgement}

We acknowledge support from the STEP UP (Strengthening Evidence for Programming on Unintended Pregnancy) Research Programme Consortium. STEP UP is funded by UKaid from the Department for International Development. 


\section{List of Abbreviations}

FP Family planning

GDHS Ghana Demographic and Health Survey

GHS Ghana Health Service

GSS Ghana Statistical Service

JSS Junior secondary school

SSS Senior secondary school 


\section{Executive Summary}

\section{Background}

Despite Ghana's decline in fertility, the most pronounced in West Africa, over a third of women of reproductive age in the country reported unmet need for family planning in 2008 . Any advances in our understanding of the causes of unmet need could have profound implications for programmes.

\section{Objectives}

This study aims to establish the relative importance of lack of access and attitudinal resistance towards use of family planning for different population and geographical strata in Ghana. It is intended to inform policy makers on the priority that should be given to behaviour change communication or improved access/information, and also helpful to interventions to reduce health concerns and fear of side effects, such as provision of broader method mix and better counselling.

\section{Methods}

Adapting the measures developed by Cleland et al. (2011), we identified whether women with unmet need for family planning have access to (defined by knowledge of pills and injectables, and supply sources), and attitudinal acceptance of (defined by intention to use in the future), family planning. We assessed variations of unmet need across different population strata. We also estimated risk ratios of having unmet need across the population strata relative to using modern contraceptives. The analyses were focused on 1294 fecund and non-pregnant non-postpartum abstaining women aged 15-49 who were married or cohabiting at the time of the 2008 Ghana Demographic and Health Survey.

\section{Results}

Forty-two percent of the women had unmet need for family planning, among whom $77 \%$ had access and $56 \%$ had attitudinal acceptance. Though current use of a modern method was higher among women who wanted no more children than among those wishing to delay the next birth, unmet need was also much higher ( $55 \%$ versus $36 \%$ ). Non-use among limiters accounted for $45 \%$ of all unmet need. There were substantial inequalities across population strata. More than $50 \%$ of women living in the Southern belt (Western, Central and Volta regions), those with no education, or women in the poorest quintile had unmet need for family planning. Problems of access were part of the explanation for high unmet need in these groups, though lack of knowledge or access was an uncommon reason given for non-use. Sixty percent of women who had a birth in the past 2 years had unmet need, and it was even higher among breastfeeding women. The dominant self-reported reason for non-use of family planning was health concerns/fear of side effects (43\%), followed by infrequent sex (17\%) and respondent's opposition (14\%). One-third of all women with unmet need had previously used pills or injectables.

Those stating infrequent sex as a reason for non-use were much more likely to have abstained in the past month. Recent abstinence was strongly related to the desire to avoid another birth for at least two years and to non-use of contraception. Temporary abstinence or reduced coital frequency appears to be an alternative to modern contraceptive use.

Though unmet need and fertility level are lower among more privileged strata (women with secondary schooling and those living in Greater Accra), modern method use has declined in these groups and traditional methods, particularly periodic abstinence, are more commonly used. 


\section{Discussion and implications}

The most far reaching implication concerns the reproductive behaviour of the best educated women and those living in the capital or surrounding areas. The results suggest an enduring resistance to the dominant hormonal methods, much of it based on experience of side effects during prior episodes of use. Many of these women prefer to use periodic abstinence, or reduced coital frequency. Their level of fertility is also much lower than implied by reported contraceptive use, suggesting that contraception is under reported and/or that abortion is common. The importance of this pattern stems from the expectation that less privileged groups in society will follow the example of elite groups, who typically are the forerunners of change. The optimal policy and programmatic response is not obvious. Experiences from other countries showed that improved counselling, for instance, has not proved effective in reducing discontinuation due to side effects (Halpern et al. 2011). There is a strong case for broadening the method-mix by promotion of non-hormonal methods, such as IUDs and sterilisation. These methods may arouse less anxiety about health than pills or injectables. Moreover, the need for long acting methods is clear cut because nearly a half of unmet need in Ghana comprises women who want no more children.

It also is likely that periodic abstinence and other ways of reducing coital frequency will continue to play an important role in overall fertility regulation. Knowledge of the fertile period has improved and this trend should be encouraged through a range of information channels. Even with accurate knowledge, unintended pregnancies will be common and thus the need for safe abortion will be high. Ghana has liberal abortion laws but their implementation in terms of service access may require improvement. 


\section{Introduction}

The majority of unintended pregnancies stem from unmet need for contraception and the prime objective of family planning programmes is to reduce unmet need. According to the Ghana DHS 2008, a third of women of reproductive age reported unmet need for family planning. Little has changed in the level of unmet need since the early 1990s. Any advances in our understanding of the causes of unmet need could have profound implications for programmes.

The main aim of this project is to establish the relative importance of lack of access and attitudinal resistance towards use of family planning in accounting for unmet need among different population strata in Ghana. The results may be useful for policy makers in deciding the priority that should be given to behaviour change communication or improved access/information for different socio-economic strata and different geographic regions, and also helpful to interventions to reduce health concerns and fear of side effects, such as provision of broader method mix and better counselling. This report presents the preliminary results of the analysis using the latest DHS data.

\section{Methods}

\section{Data}

The data collected in the 2008 Ghana DHS were used for the analysis. Women who either want no more children or don't want a child in the next two years but are not using any method of contraception are regarded as having an unmet need for family planning. A standard definition of unmet need was used, following the most recent 2012 DHS report on unmet need (Bradley et al. 2012). However, women who were pregnant, or still abstaining or amenorrheic after the most recent birth, were excluded because they were not exposed to the risk of conception at the time of the survey. Single women were also excluded because their profile of method-use is very different from that of married women and thus access cannot be measured in the same way for both groups. Specifically condoms are the main method for single women (17.6\%) but rarely used by married couples (2.4\%) (Ghana Statistical Service, Ghana Health Service and ICF Macro 2009).

\section{Unmet need for family planning}

The main analysis is to deconstruct unmet need for family planning and to establish the relative importance of lack of access and attitudinal resistance towards use of family planning. Ansley Coale (1973) suggested that fast sustained fertility transition needs a large fraction of population who are 'ready, willing and able' to use contraceptives. Following the modification by Lesthaeghe and Vanderhoeft (2001), Cleland et al.(2011) developed novel measures in order to assess the extent to which populations possess these three preconditions for use and to measure trends. We extended and adapted the approach used in an investigation of progress in family planning need, access and attitude in Africa (Cleland et al. 2011). That study developed a novel measure of physical access: knowledge of the two most widely used modern methods in sub-Saharan Africa, i.e. pills and injectables, and knowledge of a supply source of any method. Knowledge of a method-specific supply source was asked only until the $1993 \mathrm{GDHS}$. This measure is not ideal for two main reasons. First knowledge of methods may include misinformation. 
Second, the restriction to pills and injectables is obviously a partial measure of knowledge of contraceptive methods but is justified by the fact that they account for two-thirds of all modern method use by married women in Ghana and, among married non-users who intend to use in the future, only a minority of $14 \%$ mention long-acting alternatives, such as sterilisation, IUDs or implants, as their preferred method, according to the $2008 \mathrm{GDHS}$. Awareness of a source is also not ideal because it tells us nothing about travelling time or distance. Nevertheless, awareness of the two dominant methods and where to obtain them captures the two most fundamental components of access.

The 2011 study by Cleland et al. also used answers to questions on approval of family planning as the measure of favourable attitude to family planning but these questions were omitted from the most recent round of DHSs. Preliminary analysis showed that a woman's approval was strongly associated with her intention to use in the future. In the $2003 \mathrm{GDHS}, 61 \%$ of women who approved of family planning had an intention to use in the future compared with only $10.5 \%$ of those who disapproved. Clearly approval and intention are not identical, but $96 \%$ of those who intend to use approved family planning. Therefore it seems valid to interpret intention as an indicator of broader attitudinal acceptance for the purposes of this report.

Based on the measure, we identified whether the women having unmet need for family planning had access to, and attitudinal acceptance of, contraception. We divided the study population into $7 \mathrm{groups}$ : (a) unmet need: has access and attitude; (b) unmet need: has access, but not attitude; (c) unmet need: has attitude, but not access; (d) unmet need: has neither access nor attitude, (e) women using modern methods for spacing; (f) using modern methods for limiting; and (g) desire to have another child within 2 years. Categories (e) and (f) represent met need while category ( $g$ ) denotes no need. The detailed definitions can be found in Table A. 1 in Appendix.

\section{Traditional methods}

Some analysts define traditional method users as having unmet need because of the high failure rate of most methods. Use of these methods is relatively common in Ghana. According to the $2008 \mathrm{DHS}, 6.9 \%$ of all currently married women were using traditional methods, mainly periodic abstinence and use was higher among urban, educated and wealthier couples than others. We examined the correlates of use of traditional or folk method by logistic regression (Table A.2) which confirmed that women with secondary schooling had 2.5 times the odds of using a traditional method than women with no schooling. Clearly, resort to periodic abstinence largely reflects an explicit preference rather than lack of access to more effective modern methods, for reasons that may be similar to those documented in Cameroon.

Cameroonian women may prefer periodic abstinence as it conforms the local norm of modernity and selfdiscipline (Johnson-Hanks 2002). Furthermore, the question on knowledge of source of family planning was not asked of women who were using a traditional method. For these two reasons, traditional method users were excluded from the analysis.

\section{Population strata}

Variations in types of unmet need were assessed in various geographic and socio-economic population strata (residence, geographical area, respondent's education and age, household wealth, religion, a combined measure of wealth and urban-rural residence, a combined measure of education and residence) and reproductive status (parity, postpartum status, breastfeeding status, past use of a modern method). 
Regions were grouped into four based on natural geographical belts, namely Greater Accra, the Southern, Middle and Northern belts (see map in Figure A.1). Greater Accra is part of the Southern belt but it was separated because it is distinct from the other parts of the Southern belt in terms of culture and socioeconomic level.

\section{Analysis}

We first assessed associations between unmet need for family planning and various population/geographical strata within Ghana by $x^{2}$ test. Then multivariate logistic regression and multinomial logistic regression analyses were employed to estimate relative risk ratio of having unmet need to using family planning in various population strata. Moreover, reasons for non-use of family planning were explored.

\section{Results}

The analysis is based on 1294 exposed married women and who were not using traditional method (see Table A.3).

Figure 1: Unmet need, modern method use and fertility desire, Ghana DHS 2008

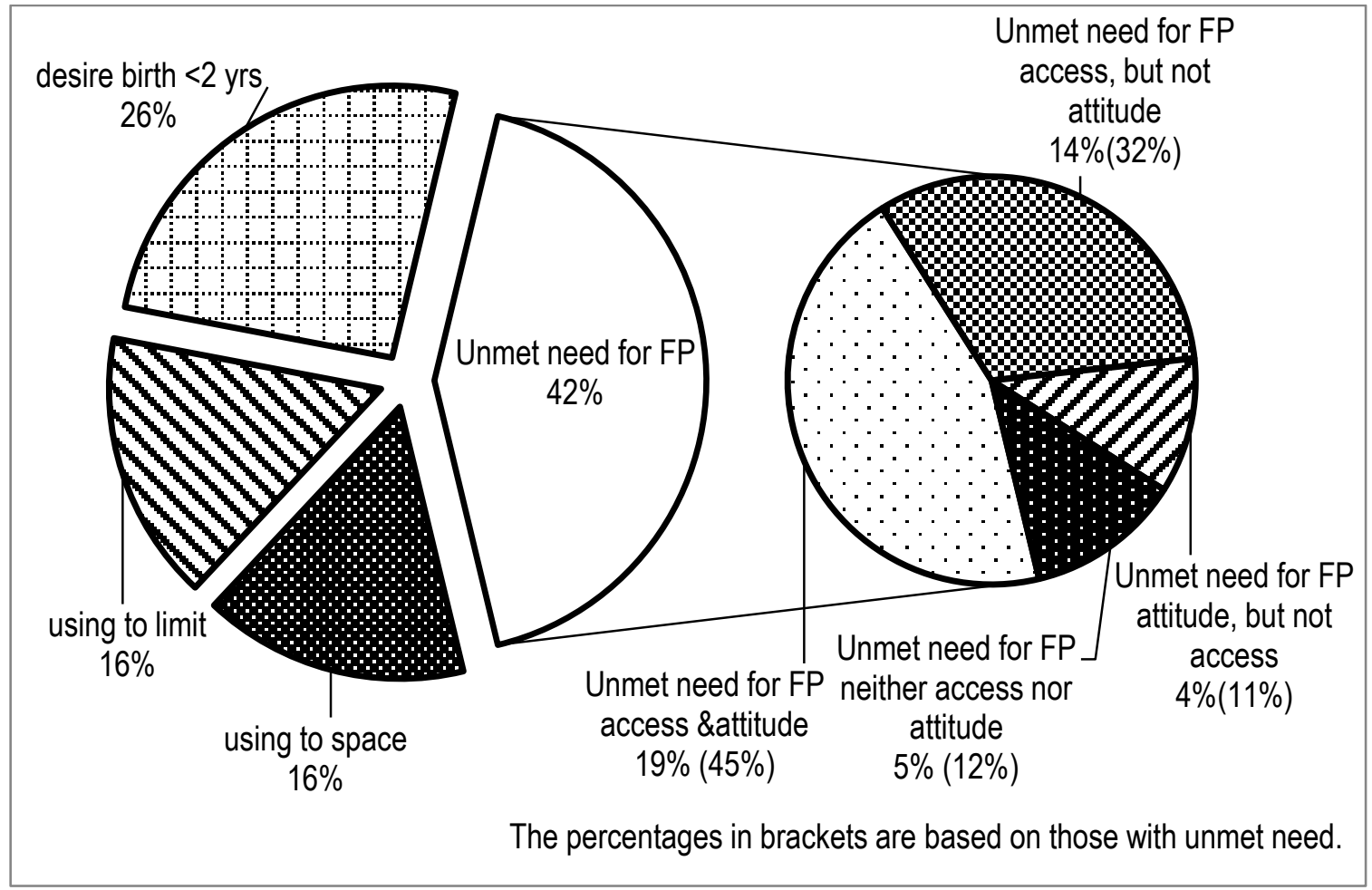


Figure 1 presents proportions of women having unmet need for family planning, using a modern method and desiring a child within the next two years. More than $40 \%$ of women had unmet need for family planning, $32 \%$ were using modern contraceptives either for spacing or limiting, and $26 \%$ desired to have a/another child within 2 years. Among those having unmet need for family planning, nearly half was classified as having access and a positive attitude and a third had access and a negative attitude. Onefifth did not have access, of whom a half had a positive attitude towards family planning use. Overall, a majority $(77 \%)$ had access and a half $(56 \%)$ intended to use family planning in the future.

Inequalities in unmet need across various population and geographical strata were substantial. Table A.4 presents distributions of unmet need, fertility preference, and modern method use by the strata. In particular, differences across geographical areas, level of mother's education, and postpartum and breastfeeding status, were large.

Regional inequality was pronounced. Unmet need was lowest in Greater Accra (31\%), highest in the Southern belt (Western, Central and Volta regions) (51\%) and intermediate at $42 \%$ in the Middle and Northern belts (see Figure 2). Noticeably, the percentage of women without access or attitude in the Southern belt was much higher than elsewhere, while the levels of the other types of unmet need were similar. The high level of unmet need in the Southern belt stems in part from the fact that fewer women $(18 \%)$ wanted another child soon (and thus had no need) than in the other three belts where close to $30 \%$ desired a child within two years. Lack of access appears to be more problematic in the Southern and Northern belts than in the Middle belt or Greater Accra.

Figure 2: Unmet need for family planning by geographical area

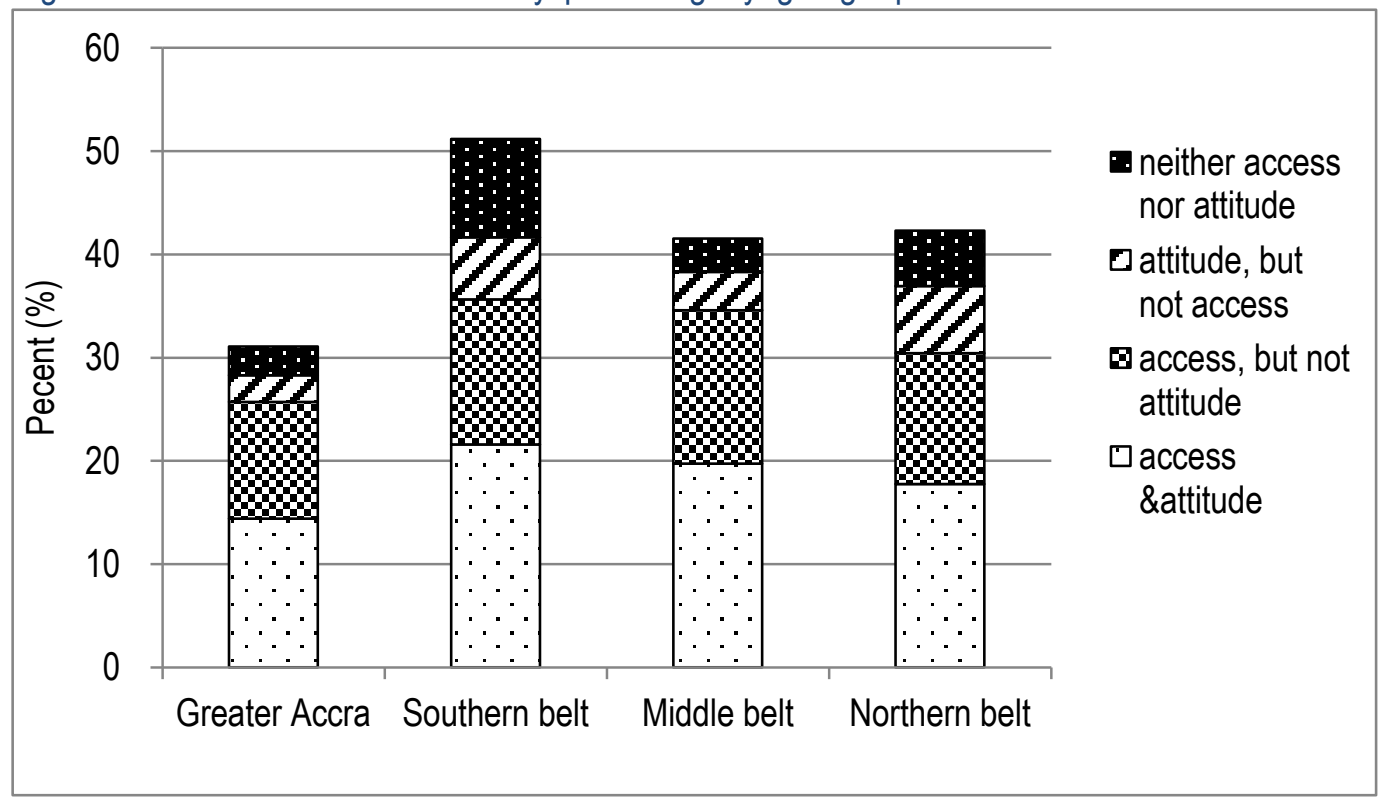

Figure 3 shows unmet need by level of mother's education. Among the married exposed women in Ghana, $24 \%$ had received no schooling, $23 \%$ had primary schooling, $39 \%$ had gone to middle or junior secondary school (JSS) and $13 \%$ had secondary school or senior secondary school (SSS) or higher education. There is a clear gradient in level of unmet need by education from $53 \%$ in the no schooling group to $31 \%$ among women with secondary or higher schooling. Lack of access accounts for more of the unmet need in less 
educated than the better educated groups. Use of a modern method is markedly lower among women with no schooling than among others. Notably, almost all women with secondary or more education had access.

Figure 4 presents gradients of unmet need by household wealth quintile. Similar to the educational groups, a montonic decline in unmet need is apparent as wealth improves which reflects greater access difficulties among poorer households.

Figure 3: Unmet need for family planning by mother's education

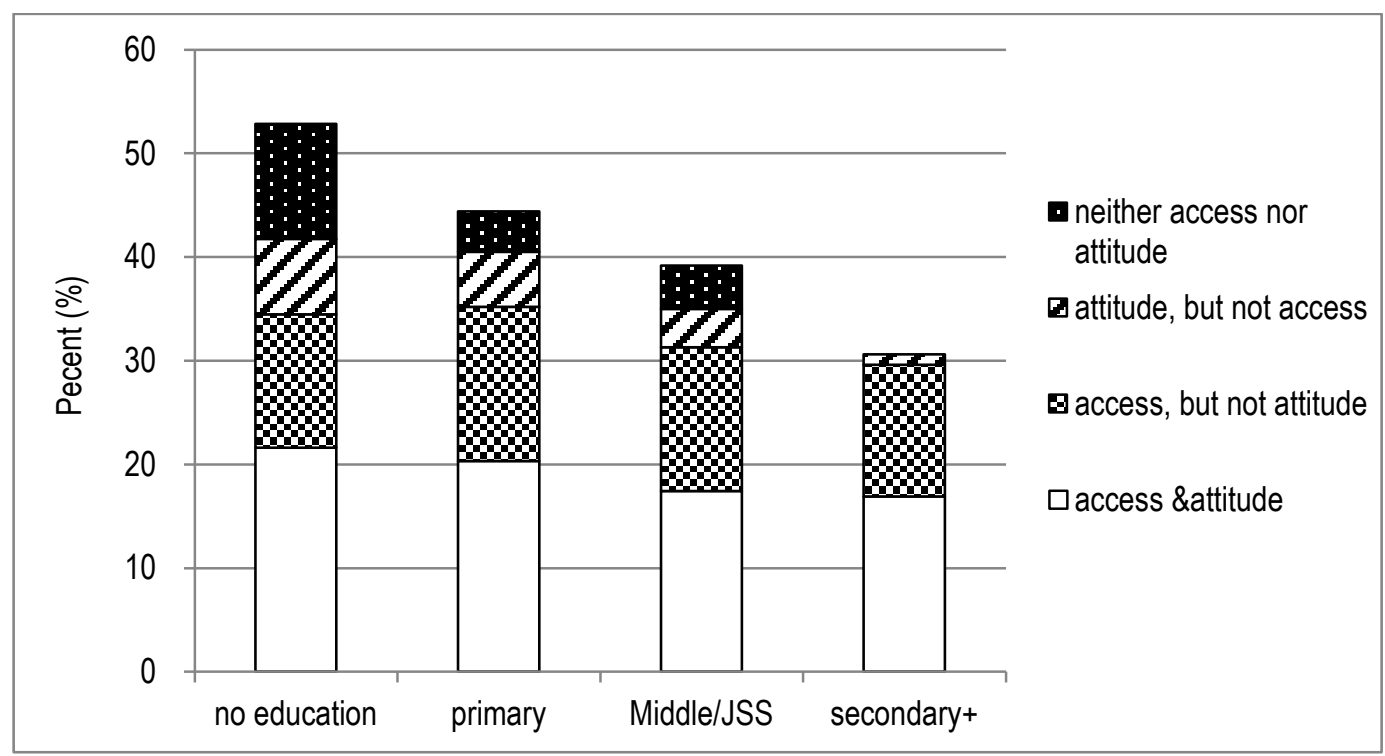

Figure 4: Unmet need for family planning by wealth quintile

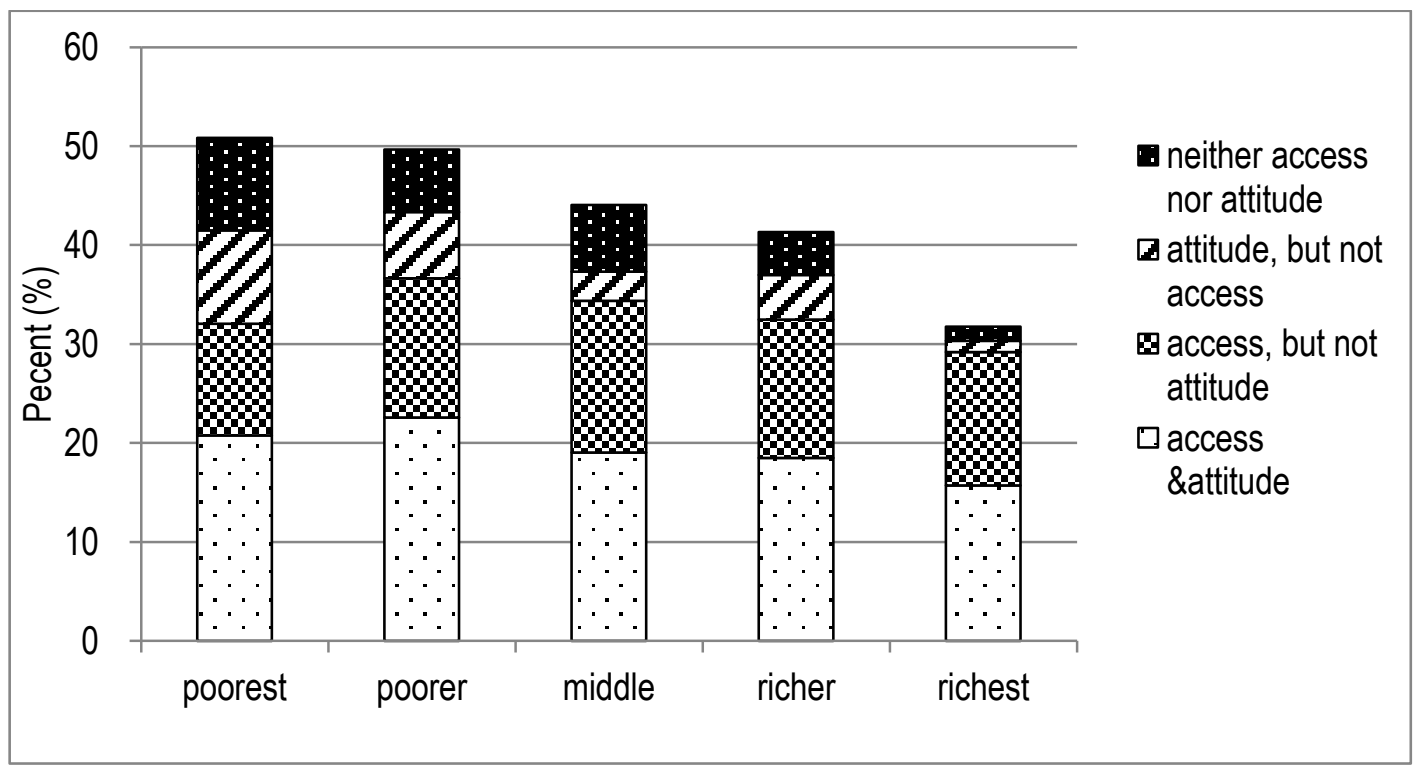

Results for the combined wealth-education-urban/rural strata are shown in Table A.4 on page 28. Among women in rural area with no schooling, $55 \%$ had unmet need and, among those, $39 \%$ did not have access. In contrast, $30 \%$ of women in urban area with secondary or more education had unmet need and, among those, only $4 \%$ did not have access. 
There was a significant difference in level of unmet need by religion (Table A.4 on page 31). The small number of adherents to traditional religions had the highest level of unmet need $(57 \%)$ and access appears to be a problem. Unmet need was lowest among Catholics (36\%) and the small "other religion" category (27\%) and current use of a modern method was high in these two groups. Unmet need was similar (43-45\% among Protestants, Other Christians and Moslems). However, more Moslem women than Christian women desired another child within 2 years (33\%) and fewer women were using family planning.

Figure 5: Unmet need for family planning by postpartum status

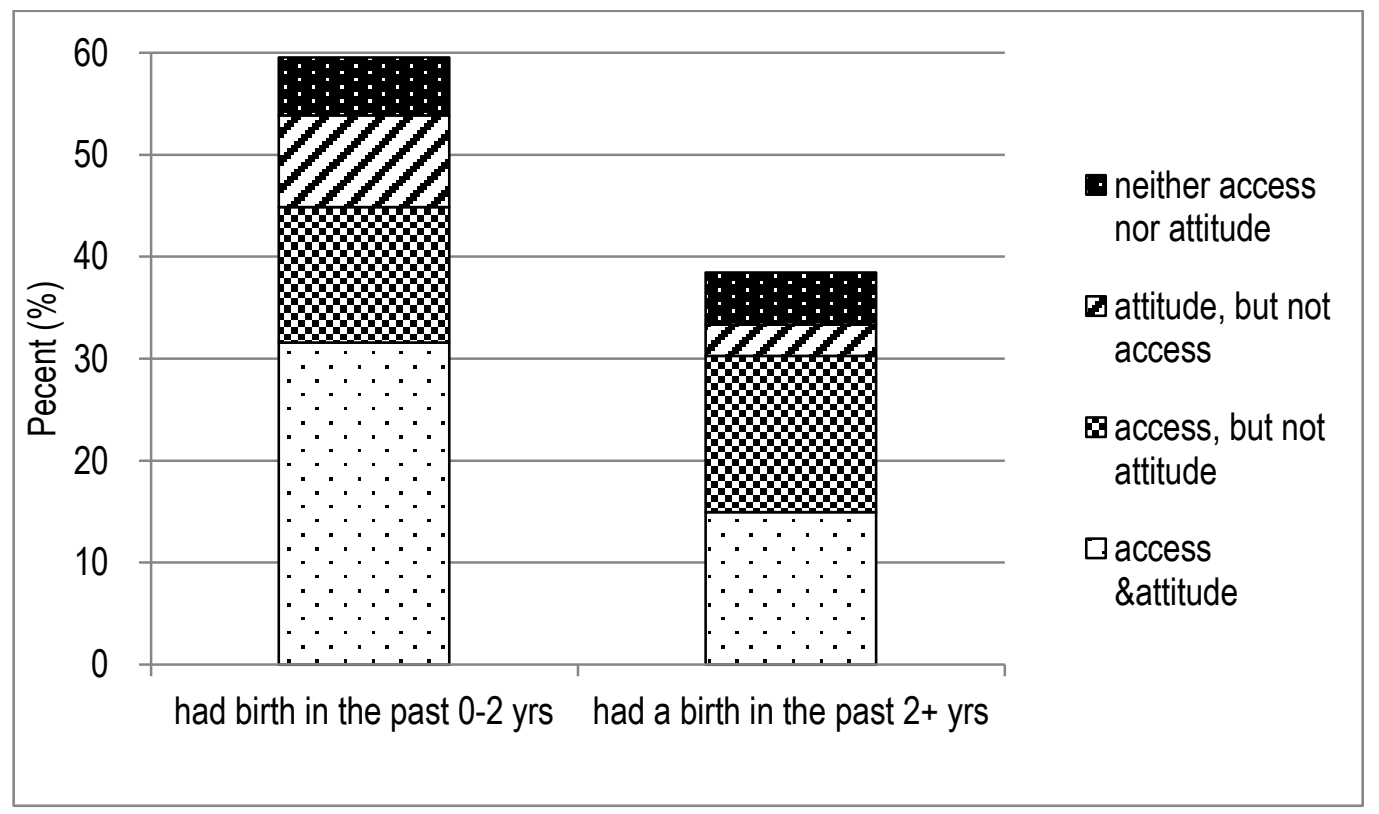

Another group with high unmet need was women who had a birth within the past 2 years. Among these women, $60 \%$ reported unmet need compared with $38.5 \%$ among the women who had a birth 2 year or more ago (see Figure 5). Over $50 \%$ of the postpartum women with unmet need had no apparent problems of access or attitude.The main reason for this contrast is that the postpartum women were much less likely to want to another child within 2 years (6\%) than those who had a birth 2 or more years ago (30\%), yet differences between the two groups in current use of family planning were negligible (see Table A.4). As presented in Table A.4, breastfeeding women with a recent birth differed little from women who had weaned their child in the level of current use and only a minor difference in unmet need. Among women whose most recent birth was 2 years or more ago, the minority still breastfeeding had higher unmet need than others.

Of all 549 exposed women with unmet need, $50 \%$ had earlier used a modern method and, among these, $74 \%$ had used pills or injectables. Thus about one-third of women in Ghana with unmet need had prior experience of one or both of the dominant hormonal methods. As shown in Figure $6,65 \%$ of the women who had never used a modern method had unmet need; of these, $35 \%$ had no access and $50 \%$ had no intention to use family planning in the future. Among the group who had prior experience of modern contraception, $32 \%$ had unmet need. Not surprisingly, very few were classified as lacking access but $40 \%$ had no intention to use in the future. 
Figure 6: Unmet need for family planning by ever use of modern family planning

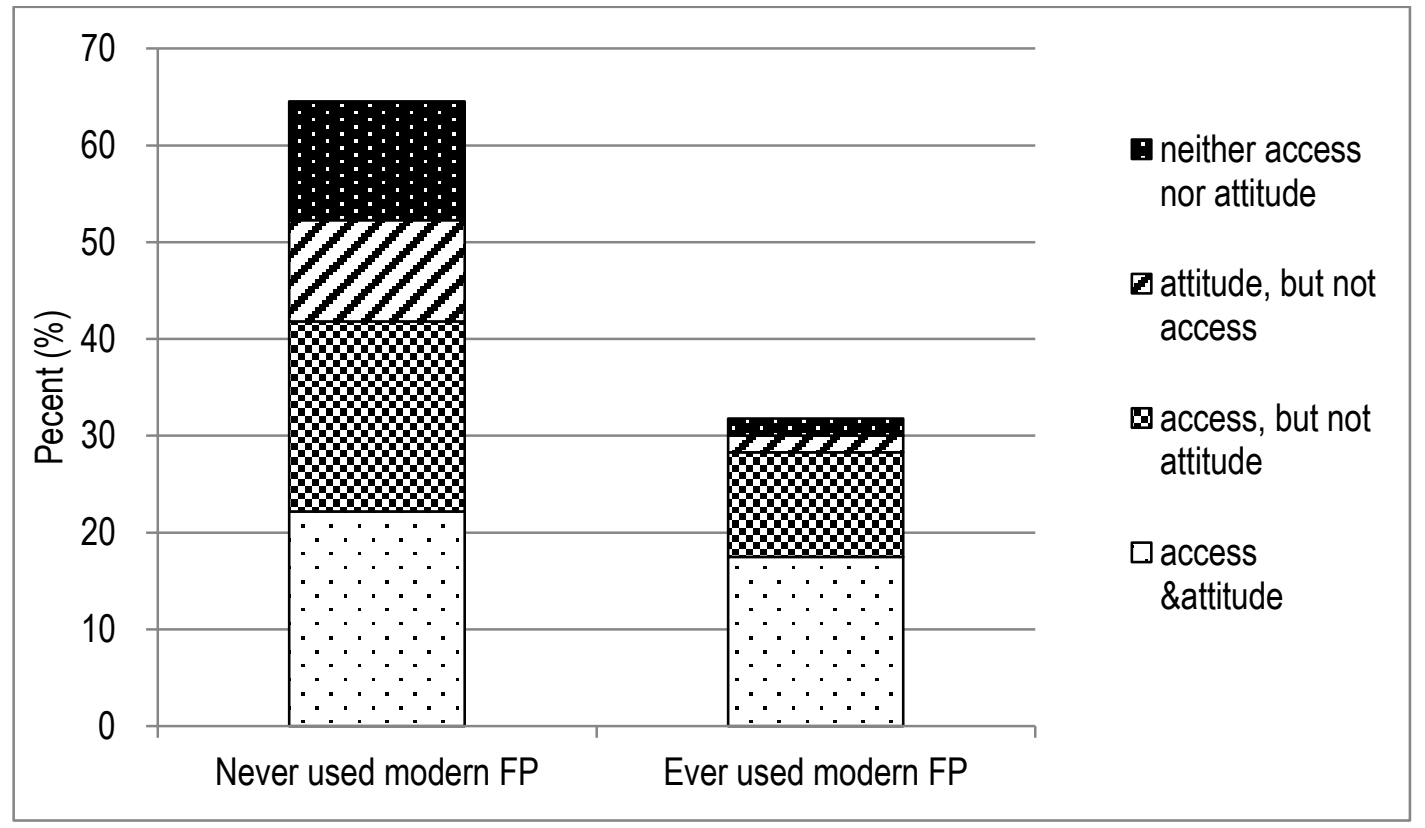

Among all 1294 exposed women, about two-thirds want another child sooner or later. Among spacers, $24 \%$ are current users compared with $45 \%$ among those wanting no more children. Despite their higher use, limiters record much higher unmet need $(55 \%)$ than spacers (36\%) because over one-third of spacers want another child within two years and therefore have no need (Table A.4). But because desire to postpone or space is more common than desire to limit, spacers account for $55 \%$ of all unmet need.

\section{Multivariate and multinomial logistic regression}

The analysis so far has been mainly descriptive. In order to more closely identify the factors that give rise to unmet need, logistic regression was applied and results are shown in Table A.5. The adjusted odds ratios indicate the association between background factors and having unmet need versus being a modern method user, after controlling for other factors.

Rather few significant effects at the $95 \%$ confidence level were found. Unmet need did not differ significantly by urban-rural residence, household wealth or by women's age or parity. The most important result concerns geographical areas. Compared with Greater Accra, unmet need was twice as high in the Southern belt and 1.7 times higher in the Middle belt. Women with no schooling had twice the odds of unmet need than women with some schooling but higher school attainment did not further diminish unmet need. Postpartum women had 1.5 times higher unmet need than others. Compared with Protestant women, Catholic women were less likely to have unmet need.

The results of a more complex multivariate analysis, using multinomial logistic regression are shown in Table A.6. Non-users were divided into five categories based on our four combinations of access and attitude, together with a fifth category of those who want a child in the next two years and thus have little or no more unmet need but a convincing reason for non-use. The adjusted relative risk ratios show the ratios of probability of being in each of these five categories of non-use relative to probability of being a modern method user. 
Relative risk ratios for women in rural areas show that, relative to women in urban areas, rural women were less likely to be in the three categories of unmet need and but more likely to want another child soon. However, these results are not statistically significant.

Generally, few significant effects at the $95 \%$ confidence level were found. The most pronounced effects concern education and postpartum status. Compared with those with some schooling, women without education were much more likely to lack access and positive attitude. Postpartum women relative to those who had birth more than 2 year or more ago were much more likely to be in the categories of unmet need with and without access, and with favourable attitude. This indicates that postpartum women had positive attitude toward family planning use, but access and the other factor appear to prevent the use, which corresponds to the self-reported reasons. Compared with those in Greater Accra, women in the Southern and Middle belts were significantly more likely to have unmet need despite having access and positive attitude. Women in the Middle and Northern belts were more likely to want another child soon.

\section{Reasons for non-use of family planning}

In answer to a question on reasons for unmet need, multiple responses were permitted and about $8 \%$ gave more than one reason (Table A.7). Nearly half of women (43\%) raised health concern or fear of side effects as a reason for non-use of family planning. Other reasons commonly mentioned were infrequent sex (17\%) and respondent's opposition (14\%) (Table 1).

Table 1 shows a comparison of the four categories of unmet need, defined in terms of access and attitude, with self-reported reasons. The reasons varied among four categories. Health concern was the most commonly cited reason across all four categories, but the levels were significantly different. $(p=0.014)$. This reason was particularly common among women with access but not positive attitude (54\%) and those with neither access nor attitude (44\%). Among women with access and favourable attitude a quarter also mentioned infrequent sex (24\%) and $13 \%$ cited breastfeeding as a reason for non-use. Not surprisingly respondent's opposition was the second most commonly mentioned reason among women with unmet need without attitude, and lack of knowledge was mentioned more often among women without access. Inconsistencies between the four-fold classification of unmet need and self-reported reasons were also apparent. Even among women who intend to use in the future, personal opposition was cited as a reason by an appreciable proportion. 
Table 1: Reasons for non-use of family planning

\begin{tabular}{|c|c|c|c|c|c|c|}
\hline \multirow[b]{2}{*}{ Reasons } & \multicolumn{4}{|c|}{ Unmet need for family planning } & \multirow[b]{2}{*}{ Total } & \multirow[b]{2}{*}{$\begin{array}{c}p \text {-value fo } \\
x^{2} \text { test }\end{array}$} \\
\hline & $\begin{array}{l}\text { access \& } \\
\text { attitude }\end{array}$ & $\begin{array}{l}\text { access, } \\
\text { but not } \\
\text { attitude }\end{array}$ & $\begin{array}{l}\text { attitude, } \\
\text { but not } \\
\text { access }\end{array}$ & $\begin{array}{l}\text { neither } \\
\text { access } \\
\text { nor } \\
\text { attitude }\end{array}$ & & \\
\hline Respondent's opposition & 8.7 & 19.2 & 15.9 & 18.6 & 14.1 & 0.063 \\
\hline $\begin{array}{l}\text { Partner's/ others' } \\
\text { opposition }\end{array}$ & 4.8 & 2.6 & 5.2 & 7.9 & 4.5 & 0.475 \\
\hline Lack of knowledge & 4.6 & 0.9 & 14.4 & 11.4 & 5.2 & 0.002 \\
\hline Lack of access/cost & 6.8 & 2.8 & 7.2 & 2.9 & 5.1 & 0.373 \\
\hline \multicolumn{7}{|l|}{$\begin{array}{l}\text { Health concerns/fear of } \\
\text { side effect/interfere with }\end{array}$} \\
\hline body & 36.6 & 53.8 & 32.4 & 44.2 & 42.7 & 0.014 \\
\hline Infrequent or no sex & 23.5 & 11.8 & 9.4 & 10.2 & 16.6 & 0.034 \\
\hline Breastfeeding & 12.5 & 2.4 & 4.0 & 3.3 & 7.3 & 0.001 \\
\hline Others/don't know & 7.4 & 3.4 & 10.8 & 1.7 & 5.8 & 0.072 \\
\hline $\mathrm{N}$ & 216 & 157 & 51 & 55 & 479 & \\
\hline
\end{tabular}

Note: 71 women did not answer the questions. Women may provide multiple answers.

Figure 7: Reasons for non-use of family planning by geographical area

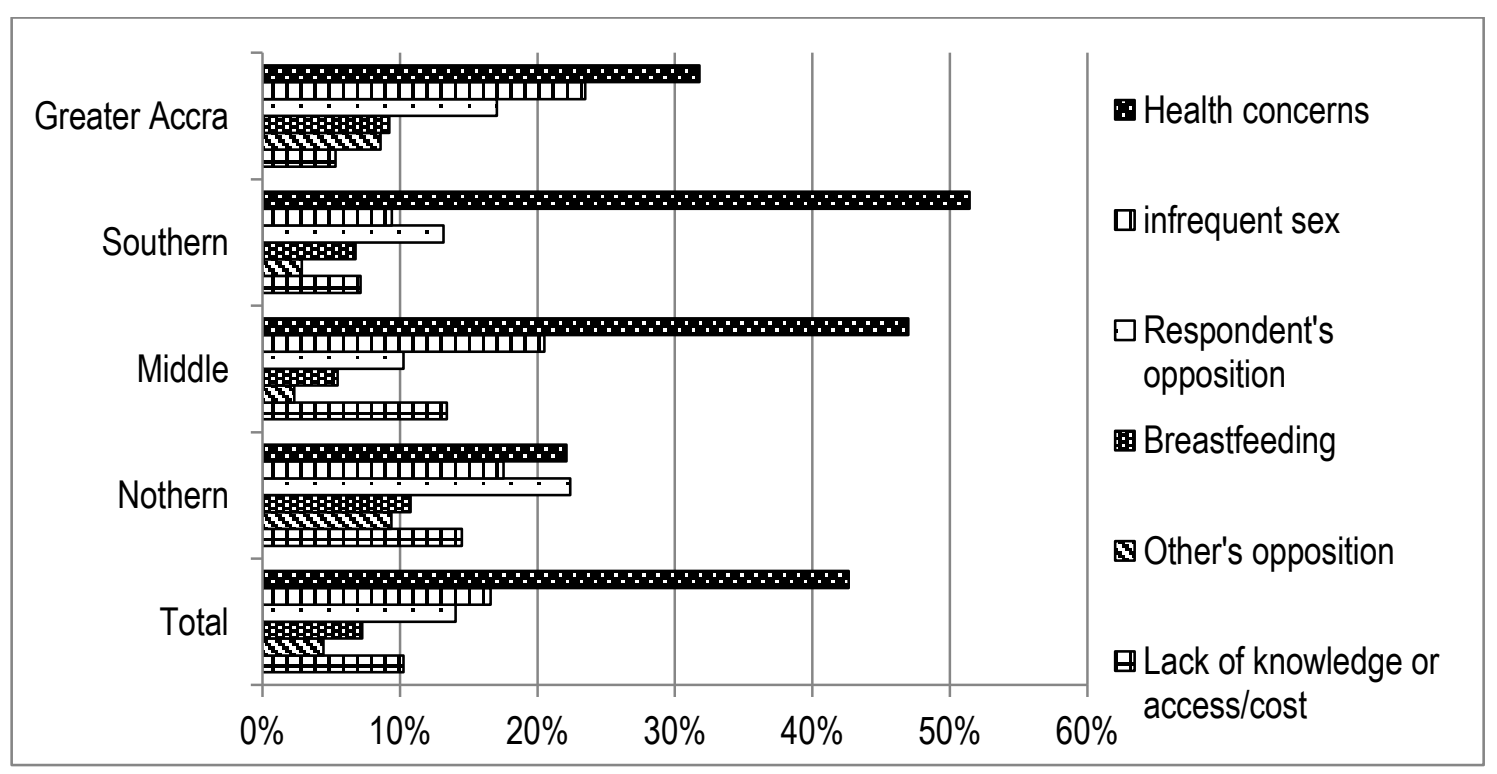

Figure 7 presents reasons for non-use of family planning by geographical area. Health concerns were the dominant reason in all geographical areas except in the Northern belt, and also less predominant in Greater Accra. This reason was cited most commonly in the Southern belt, where unmet need was the highest. In contrast, more women mentioned infrequent sex in Greater Accra and the Middle belt than elsewhere. Respondent's opposition was most commonly given as a reason in the Northern belt and in Greater Accra. 
Figure 8: Reasons for non-use of family planning by postpartum status

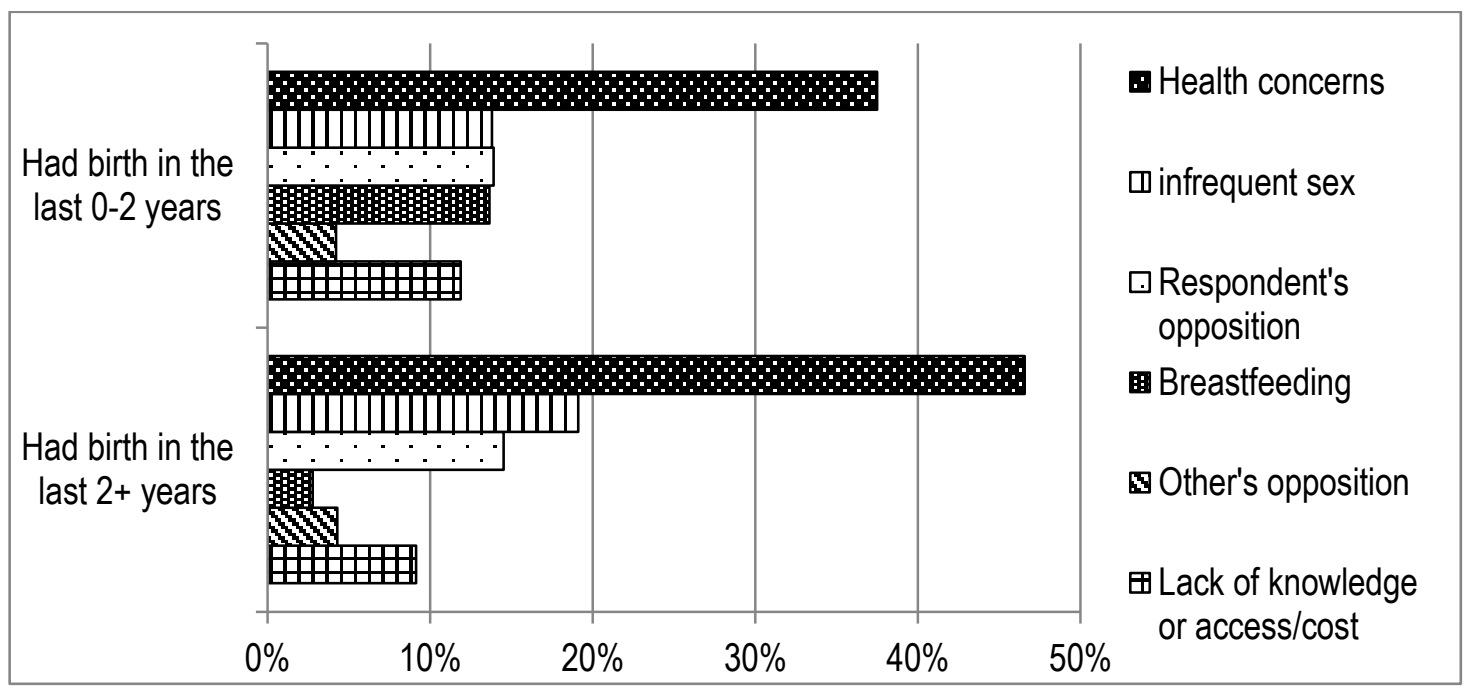

Figure 8 shows reasons for non-use by postpartum status. The majority of women in both groups raised health concerns. Breastfeeding was more often cited by postpartum women than by women who had a child 2 or more years ago. Surprisingly, the proportion of women who mentioned health concerns and infrequent sex among women who had a birth 2 or more years ago was higher than among those in postpartum period. Only breastfeeding was significantly associated with postpartum status.

Figure 9: Reasons for non-use of family planning by prior experience of modern method use

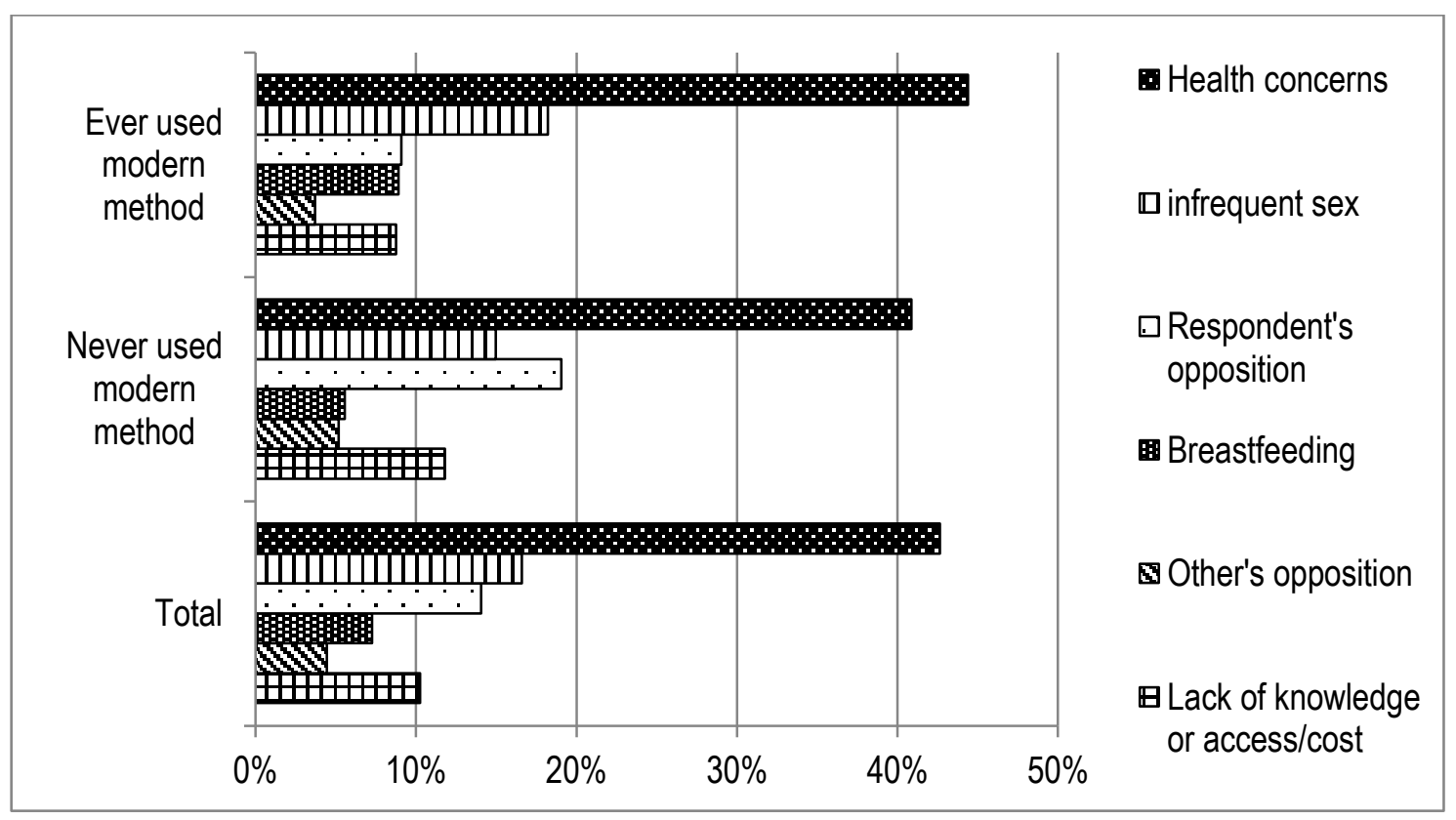

Figure 9 shows reasons by prior use of a modern method. Generally the profiles were similar with health concerns dominant in prior users and non-users. However, respondent's opposition and lack of knowledge or access/cost was more common among women who had never used a modern method before. 
Figure 10: Reasons for non-use of family planning by mother's education

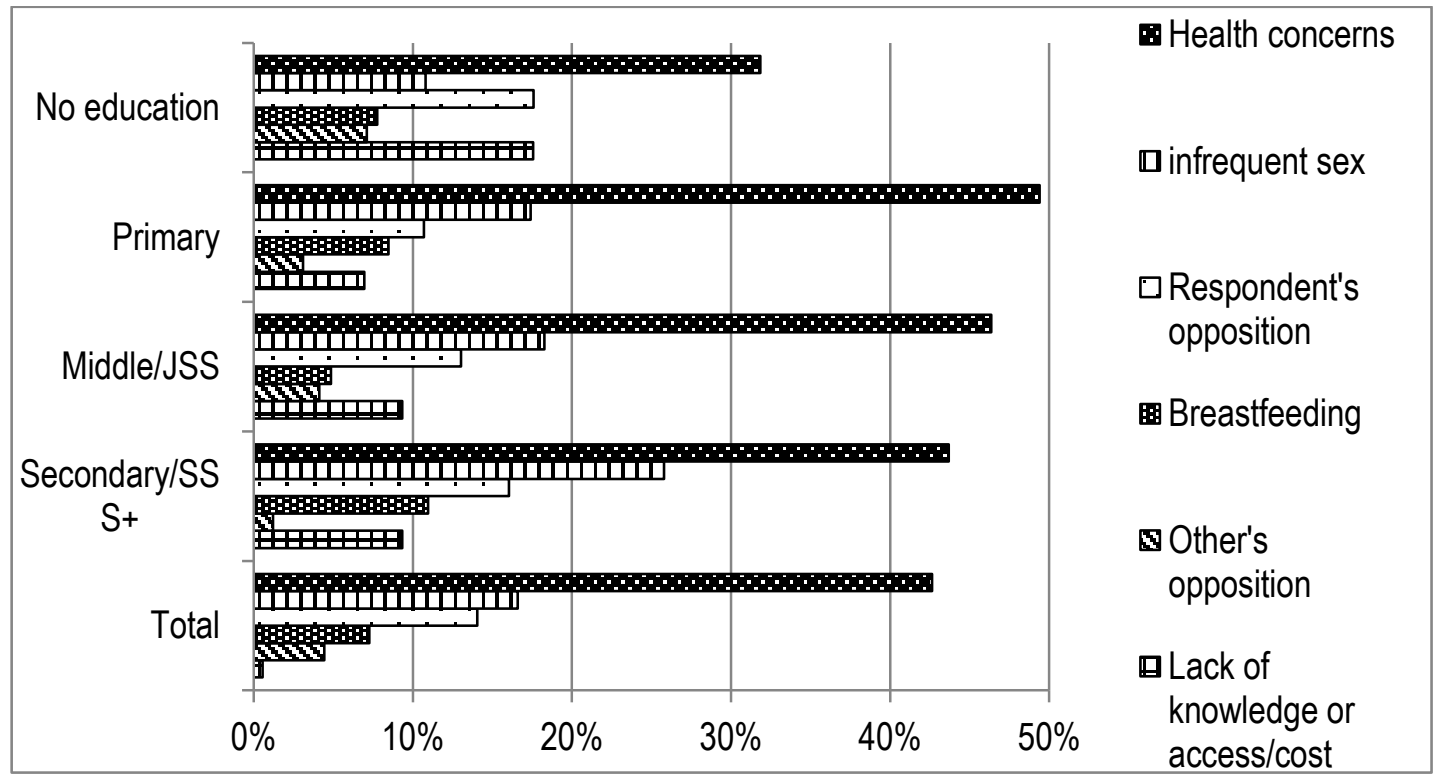

Figure 10 shows reasons by mother's level of education. Again health concerns are the most common reason for non-use across all educational groups. It is clear that a high level of education does little to diminish concerns about health or side-effects. Respondent's opposition was most frequently cited by women with no schooling and by those with secondary or higher schooling. This unexpected pattern may explain the popularity of traditional methods among the best educated women (see Table A.2). Lack of knowledge was a commonly mentioned reason only among women with no education. Reporting of infrequent sex rose by educational level and this reason was mentioned by more than $25 \%$ of women with secondary or higher education.

\section{Infrequent Sex}

Infrequent sex was often mentioned as a reason for use in Ghana. As a partial check on the validity of this response, answers to an independent question on recency of last sex were examined. Women citing infrequent sex were indeed much less likely than others to report sex in the preceding 4 weeks (Table 2). Nevertheless one-third did report sex in the recent past.

Table 2: Recency of last sex by whether infrequent sex was given as a reason for non-use

\begin{tabular}{lccc}
\hline & \multicolumn{2}{c}{$\begin{array}{c}\text { Reason for non-use: } \\
\text { Infrequent sex }\end{array}$} & \\
\cline { 2 - 3 } Recency of last sex & No & Yes & Total \\
\hline in last 4 weeks & 71.3 & 32.6 & 64.8 \\
in last 3 months & 19.8 & 28.9 & 21.3 \\
4 or more months ago & 6.2 & 34.0 & 10.8 \\
before last birth & 0.0 & 1.6 & 0.3 \\
Missing & 2.7 & 2.9 & 2.8 \\
\hline Total & 100.0 & 100.0 & 100.0 \\
\hline $\mathrm{N}=479$ & & &
\end{tabular}


To test the hypothesis that infrequent sex is used as an alternative to contraception, we examined the correlates of sexual abstinence in the preceding month by logistic regression (Table A.8). Residential status was a strong predictor of not having sex in the past 4 weeks. Woman reporting that their husband was staying elsewhere, in answer to the question "is your husband/partner living with you now or is he staying e/sewhere?', were four times more likely to have abstained from sex in the last 28 days than others. But after adjustment for residential status, contraceptive use, residence, parity, postpartum status and other factors, significant associations were found between desire for, and timing of, another child and abstinence. Compared with women who wanted the next child soon, those who wanted to delay for 2 years or more, or wanted no more were twice as likely to report abstinence. Moreover, non-users of contraception were twice as likely to report abstinence as users. Women in urban area were also more likely to report abstinence than rural women, but educational differentials were not significant. These results provide some support for the view that reduced coital frequency is deployed in Ghana as an alternative to contraceptive methods.

\section{Discussion and Implications}

Ghana is the forerunner of fertility decline in West Africa with a recorded fall in the total fertility rate of over two births since the 1980s. However this decline has occurred with sustained low levels of reported contraceptive use (Blanc and Grey 2002). Though fertility has continued its decline since 2000, albeit at a slower pace than in the late 1980s and early 1990s, use of modern methods actually fell between 2003 and 2008, particularly among better educated and urban women (ICF Macro 2010). Indeed, reported use has fallen steeply and steadily among women with secondary or higher schooling since 1993, initially because a large decline in reported use of periodic abstinence, yet the total fertility rate in this stratum was estimated to have dropped from 2.5 to 2.1 between the early and mid-2000s. These trends suggest two tentative conclusions: an enduring resistance, or ambivalence, to modern methods of contraception, among urban, educated women; and resort to means of controlling reproduction that are not reported in national surveys. Can this investigation of unmet need provide any new insights?

Despite the decline in fertility, the 2008 DHS reveals nearly one-quarter of births were mistimed and $14 \%$ unwanted. In this analysis, confined to married women exposed to the risk of pregnancy at the time of the survey, $42.5 \%$ were classified as having unmet need for family planning, $32 \%$ were using a modern method and $26 \%$ wanted to have another child within two years. This estimate of unmet need is very similar to that that of unmet need for modern methods given in the DHS Analytical Report (42.6\%) (Bradley et al. 2012).

Forty-five percent of the total number of women with unmet need reported knowledge of pills and injectables, knew of a supply source and stated an intention to use in the future. Thus neither access nor attitude appears to provide a ready explanation for non-use in this group. Two-thirds of them had used a modern method in the past, predominantly pills or injectables $(73 \%)$. The main reason for non-use was health concerns and fear of side effects, an answer given by $37 \%$ to the direct question on reasons for non-use. In view of the high level of past use of hormonal methods among these women, discontinuation because of side-effects experienced with hormonal methods is probably a major reason for unmet need. Fear of side effects or health concerns were just as likely to be cited as reasons for non-use among women who had never used a modern method suggesting that concerns about side effects spread from 
past users to non-users. Nevertheless, $70 \%$ of married women intending to use in the future specified a hormonal method as their preference (the result not shown). This may also reflect the limited availability of non-hormonal method. For instance, IUD was available in only $36 \%$ of the facilities in the country according to the 2002 Ghana SPA (Ghana Statistical Service, Health Research Unit Ministry of Health and ORC Macro 2003). Though the predictive validity of intentions is unknown, these findings suggest that unmet need may reflect a temporary abandonment of hormonal methods rather than a permanent rejection.

The next largest category of unmet need, accounting for about one-third of all unmet need, comprised women who had access but did not intend to use in the future. About half in this group were past users of a modern method. Health concerns and side effects were an even more dominant reason for non-use than for women who intended future use and were cited by $54 \%$. About one-fifth of this group offered personal opposition as their reason. For many Ghanaian women, it appears that past experience of side effects or concerns derived from the experience of past users, perhaps inflated by rumour, act as a serious impediment to future use.

The third major category of unmet need, accounting for $23 \%$ of the total, were women who either were unaware of the two main methods or had no knowledge of a supply source. This group is evenly divided between those who intend and do not intend to use in the future. Again, health concerns were the most common reason for non-use, followed by personal opposition and lack of knowledge.

Among all women with unmet need, infrequent sex was given as a reason by $17 \%$, rising to about $25 \%$ among women in Greater Accra, those with secondary or higher schooling and those who had both access and a positive attitude. Comparison with an independent question on recency of last sex shows that only $33 \%$ of women giving this reason for non-use reported sex in the past month compared with $71 \%$ of the other women. Multivariate analysis of the correlates of recent sexual abstinence found that abstinence among those wishing to postpone the next birth for 2 years or more or want no more children was more than twice as common as that among those wanting another child soon. Similar results were found in the analysis by Blanc and Grey (2002). Abstinence was also much higher among non-users than users of modern contraception. These results suggest that abstinence, or reduced coital frequency, may be deployed as a partial substitute for contraception.

As expected, unmet need declines from about $50 \%$ among the poorest women and those with no schooling to about $30 \%$ among the richest and best educated. It is also lowest in Greater Accra, the most developed area. These gradients appear at first glance to be consistent with the low fertility level of 2.5 in Greater Accra and 2.1 among women with secondary or higher schooling. However, interpretation needs to take account of traditional method use (excluded from this analysis), the apparent fall in contraceptive use documented in DHSs among the urban and better educated, and fertility preferences. Current use of a modern method by married exposed women differed little between those with primary, middle and secondary schooling. What accounts for the low level of unmet need among the best educated is that a higher proportion wants another child soon. The multivariate results in Table A.8 show no difference in desire for a child in the next two years between the three schooling categories after adjustment for parity and other confounders, suggesting that the high desire for another child simply reflects the fact that women with secondary or higher schooling are younger and have smaller families.

Traditional method use is common in Ghana. The 2008 DHS shows that $6.9 \%$ of currently married were using any type of traditional method and $4.7 \%$ using periodic abstinence. The latter's popularity does not stem from religious doctrine. Compared with women from other Christian denominations, Catholics were more likely to use modern methods but no more likely to use traditional ones. Reported use of periodic 
abstinence was twice the national average among the best educated stratum and was also higher in Greater Accra than elsewhere; this analysis confirms these descriptive findings in the 2008 DHS report. Among currently married women in Greater Accra, the most popular method was periodic abstinence $(9.3 \%)$, followed by condom (6.1\%), pill (6.0\%) and injectables (6.0\%). The profile of current use in secondary schooled women is very similar. Moreover, $70 \%$ of users of periodic abstinence have correct knowledge of the fertile period.

The implications of these results are far reaching. It appears likely that many couples who belong to the most privileged strata of Ghanaian society distrust hormonal methods because of side effects and health concerns and are achieving small family sizes through methods that are seen to pose fewer threats to health. These methods include reduced coital frequency (facilitated by the fact that a large minority of urban women live in different households from their husbands), periodic abstinence, condoms and abortion which is thought to be common in Ghana. It is also likely that these methods are under reported by women.

This interpretation is supported by a qualitative study in Accra of 26 men and 54 women, of whom about half were currently married (Osei 2009). Reported side effects of injectables mainly concerned menstrual disruption while those associated with the pill included headache, weakness and nausea. Some women persisted with use despite these side effects but many discontinued. The respondents reported a total of 156 pregnancies; 94 were unintended, of which 53 were aborted. Thus in this study $36 \%$ of all pregnancies were terminated.

Fertility transitions powered to a major extent by use of less effective methods, with abortion as a back-up, have been rare since highly effective methods became available in the 1960s, though Albania is an exception. Nevertheless it is possible that Ghana may follow this pathway. Better educated, wealthier, urban couples are typically in the vanguard of change and their behaviour acts as a powerful example to less privileged strata. A more likely scenario, however, is that different social strata will follow varying behavioural pathways to lower fertility, with a greater preference for less effective methods among elite groups. Ghana is not unique in this positive link between high status and traditional method choice. Both India and Iran, for instance, show a similar pattern (Erfani and Yuksel-Kaptanoglu 2012). Small family sizes can be achieved by ineffective methods but access to safe abortion is a critical consideration. Even if knowledge of the fertile period can be further improved, unintended pregnancies will be common. Ghana has liberal abortion laws but it is uncertain whether access to safe terminations is widespread.

Whether or not this speculation is correct, the finding that one-fifth of exposed married women with unmet need lack even the basic components of access to modern methods should not be overlooked. This lack of access largely accounts for high unmet need among poor women and those with no schooling. It is also part of the explanation for high unmet need in the Southern belt; contraceptive use in this belt is no lower than in the Middle or Northern belts but need is greater because significantly fewer women want another child soon. Expansion of access/information is needed to meet the needs of the disadvantaged.

Unmet need was found to be higher among women who had a child in the two years prior to the survey. Fear of using a modern method while breastfeeding may be part of the explanation but surprisingly the multivariate analysis showed that lack of access was significantly higher among postpartum women than others. A sharper focus on postpartum family planning services is called for.

Ghana is unusual in West Africa in that nearly half (45\%) of unmet need stems from non-use among women who want no more children rather than from who want to postpone childbearing. The need for limitation has been rising. The percent of all married women with three or four children who wish to cease 
further childbearing rose from $25 \%$ in 1988 to $48 \%$ in 1993 and further to $57 \%$ in 2008 (Westoff 2010). Their contraceptive needs are not well served by pills, injectables, condoms or traditional methods.

Unfortunately, more appropriate long acting methods are rarely used. IUD use has declined (Gyapong et al. 2003) and use of implants and sterilisation has increased very modestly in the past 15 years. It is uncertain whether or not these methods arouse the same health concerns as pills and injectables appear to do but a strong case for a broader method-mix can be made. 


\section{References}

Blanc, A.K.and S. Grey. 2002. Greater than expected fertiltiy decline in Ghana: untangling a puzzle. Journal of Biosocial Science 34(4):475-495.

Bradley, S.E.K., T.N. Croft, J.D. Fishel, and C.F. Westoff. 2012. Revising unmet need for family planning. DHS Analytical Studies. No.25. Calverton, MD: ICF Macro. Retrieved from http:www.measuredhs.com/pubs/pdf/AS25/AS25[12June2012].pdf.

Cleland, J.G., R.P. Ndugwa, and E.M. Zulu. 2011. Family planning in sub-Saharan Africa: progress or stagnation? Bulletin of the World Health Organization 89(2):137-143.

Coale, A.J. 1973. The demographic transition reconsidered. (Eds). International Union for the Scientific Study of Population, Liege, Belgium.

Erfani, A.and I. Yuksel-Kaptanoglu. 2012. The use of withdrawal among birth limiters in Iran and Turkey. Studies in Family Planning 43(1):21-32.

Ghana Statistical Service, Ghana Health Service, and ICF Macro. 2009. Ghana Demographic and Health Survey 2008. Accra, Ghana: GSS, GHS and ICF Macro. Retrieve from http://www.measuredhs.com/pubs/pdf/SR172/SR172.pdf.

Ghana Statistical Service, Health Research Unit Ministry of Health, and ORC Macro. 2003. Ghana Service Provision Assessment Survey 2002. Calverton, Maryland: GSS and ORC Macro. Retrieved from http://www.measuredhs.com/pubs/pdf/SPA6/SPA6.pdf.

Gyapong, J., G. Addico, I. Osei, M. Abbey, D.A. Kobinah, H.O. Agyarko, G.Q. Asare, H. Birungi, and I. Askew. 2003. An assessment of trends in the use of the IUD in Ghana. FRONTIERS Final Report. Washington, DC: Population Council. Retrieved from http://www.popcouncil.org/pdfs/frontiers/FR_FinalReports/Ghana_IUD.pdf.

Halpern, V., D.A. Grimes, L. Lopez, and M.F. Gallo. 2011. Strategies to improve adherence and acceptability of hormonal methods of contraception. Cochrane Database Systematic Revew. Issue 4. Retrieved from www.who.int/rhl/reviews/CD004317.pdf.

ICF Macro. 2010. Trends in demographic, family planning and health indicators in Ghana,1960-2008: Trend analysis of demographic and health survey data. Calverton, Maryland, USA: ICF Macro. Retrieved from http://www.measuredhs.com/pubs/pdf/TR6/TR6.pdf.

Johnson-Hanks, J. 2002. On the modernity of traditional contraception: time and the social context of fertility. Population and Development Review28:229-249.

Lesthaeghe, R.and C. Vanderhoeft. 2001. Ready, willing, and able: a conceptualization of transitions to new behavioral forms. Pp. 240-264. in J.B. Casterline (Eds). Diffusion processes and fertility transition: selected perspectives, Washington, D.C.: National Academy Press.

Osei, I.F. 2009. "Exploring the opportunities and challenges to the use of emergency contrcaeption in Accra, Ghana." PhD thesis. University of London.

Westoff, C.F. 2010. Desired number of children: 2000-2008. DHS Comparative Reports. No. 25. Calverton, Maryland, USA: ICF Macro. Retrieved from http://www.measuredhs.com/pubs/pdf/CR25/CR25.pdf. 


\section{Appendix}

Figure A.1. Map of Ghana

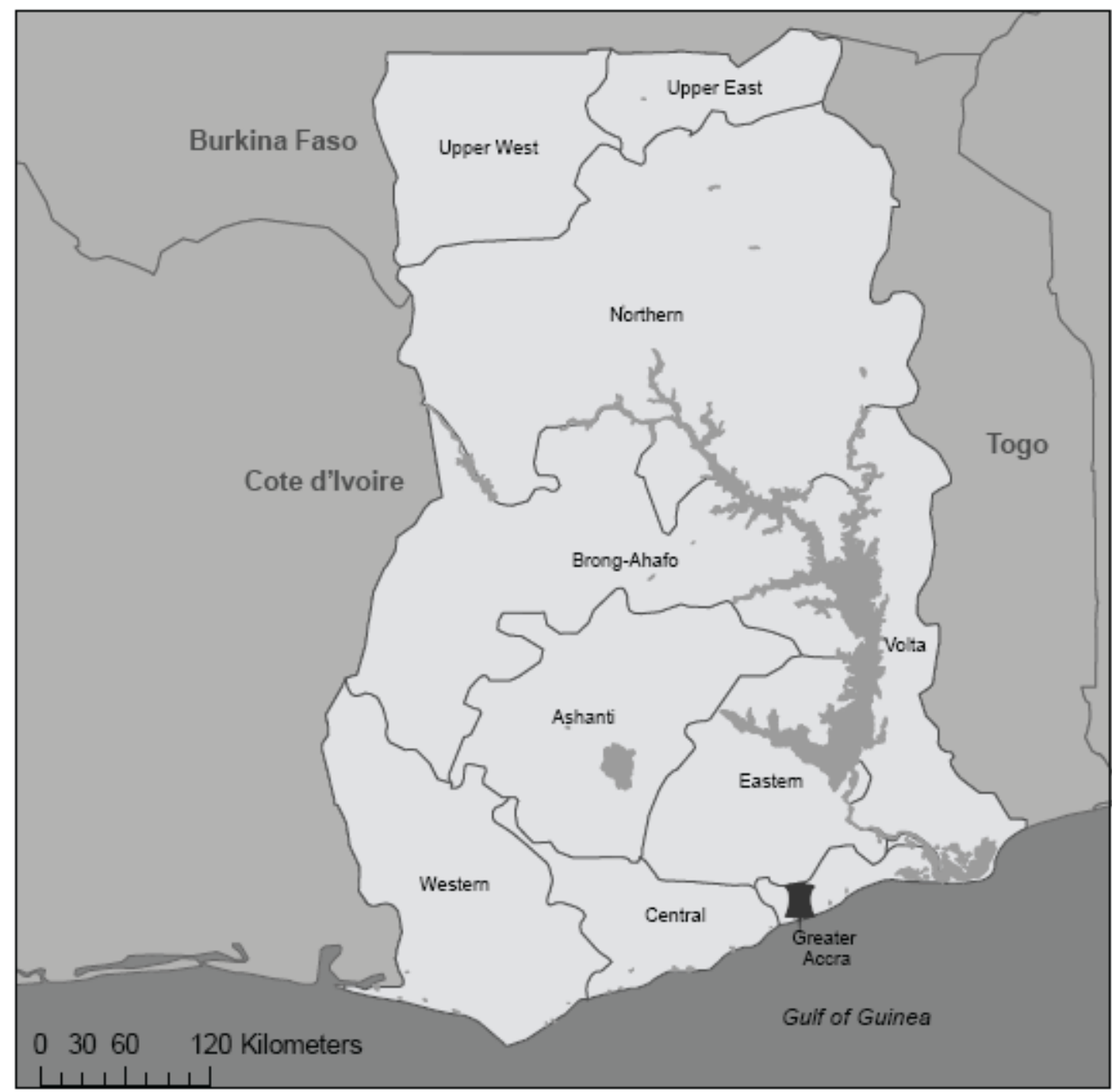

Greater Accra: Greater Accra

Southern belt: Western, Central and Volta Regions

Middle belt: Eastern, Ashanti and Brong-Ahafo Regions

Northern belt: Northern, Upper East and Upper West Regions

Source: Ghana DHS 2008 
Table A.1: Definition of indicators used for the analysis (All indicators are confined to fecund/non-pregnant, non-abstaining currently married or co-habiting women)

\begin{tabular}{l|l|l}
\hline \multicolumn{1}{|c|}{ Indicator } & \multicolumn{1}{c}{ Definition } \\
\hline 1 & $\begin{array}{l}\text { Unmet need for FP (access \& } \\
\text { attitude) }\end{array}$ & $\begin{array}{l}\text { \% of all women who have access and attitude to FP use and } \\
\text { want to delay next child for at least 2+ year, but NOT using } \\
\text { modern method among all women }\end{array}$ \\
\hline 2 & $\begin{array}{l}\text { Unmet need for FP (access \& but } \\
\text { not attitude) }\end{array}$ & $\begin{array}{l}\text { \% of all women who have access, but do have attitude to FP } \\
\text { use and want to delay next child for at least 2+ year, but NOT } \\
\text { using modern method among all women }\end{array}$ \\
\hline 3 & $\begin{array}{l}\text { Unmet need for FP (attitude, but not } \\
\text { access) }\end{array}$ & $\begin{array}{l}\text { \% of all women who have attitude, but do not have access to } \\
\text { FP use and want to delay next child for at least 2+ year, but } \\
\text { NOT using modern method among all women }\end{array}$ \\
\hline 4 & $\begin{array}{l}\text { Unmet need for FP (neither access } \\
\text { nor attitude) }\end{array}$ & $\begin{array}{l}\text { \% of all women who have neither access nor attitude to FP } \\
\text { use and want to delay next child for at least 2+ year, but NOT } \\
\text { using modern method among all women }\end{array}$ \\
\hline 5 & $\begin{array}{l}\text { Want another child and using } \\
\text { modern method }\end{array}$ & $\begin{array}{l}\text { \% of all women who want another child and using modern } \\
\text { method among all women }\end{array}$ \\
\hline 6 & $\begin{array}{l}\text { Want no more children and using } \\
\text { any modern method for limiting }\end{array}$ & $\begin{array}{l}\text { \% of all women who want no more child and using modern } \\
\text { method among all women }\end{array}$ \\
\hline 7 & Desire a birth within 2 years & $\begin{array}{l}\text { \% of all women who want another child within 2 years among } \\
\text { all women (excluding modern contraceptive current users) }\end{array}$ \\
\hline
\end{tabular}

Table A.2: Adjusted odds ratios for currently using traditional or folkloric method vs non-users

\begin{tabular}{lr|r|lll}
\hline & & Adjusted OR & \multicolumn{2}{|c}{$95 \% \mathrm{Cl}$} & \\
\hline Residence (ref. urban) & Rural & 1.05 & 0.70 & 1.57 & \\
Area (ref. Southern) & Greater Accra & 1.63 & 0.94 & 2.85 & \\
& Middle & 1.31 & 0.82 & 2.07 & \\
& Northern & 0.09 & 0.03 & 0.31 & $* * *$ \\
Education (ref. no education) & Primary & 2.22 & 1.16 & 4.25 & $*$ \\
& Middle/JSS & 1.80 & 0.97 & 3.35 & \\
& Secondary/SSS+ & 2.45 & 1.14 & 5.26 & $*$ \\
Religion (ref. Protestant) & & & & \\
& Catholic & 0.95 & 0.50 & 1.77 & \\
& Other Christian & 0.85 & 0.49 & 1.48 & \\
& Moslem & 0.69 & 0.33 & 1.42 & \\
& Traditional/spiritualist & 2.25 & 0.74 & 6.85 & \\
& Other & 1.15 & 0.38 & 3.47 & \\
\hline
\end{tabular}

$\mathrm{N}=1046$

$p<0.05,{ }^{* *} p<0.01,{ }^{* *} p<0.001$ 
Table A.3: Distributions of women, Ghana DHS 2008

\begin{tabular}{|c|c|c|c|}
\hline & & Weighted N & $\%$ \\
\hline \multirow{7}{*}{ 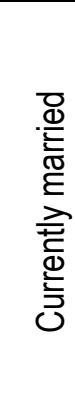 } & Exposed to pregnancy risk at survey & 1294 & 26.3 \\
\hline & $\begin{array}{l}\text { Fecund \& not postpartum abstaining, but data on } \\
\text { knowledge of a supply source or intention for future FP }\end{array}$ & & \\
\hline & use were not collected or missinga & 163 & 3.3 \\
\hline & Fecund \& postpartum abstaining & 179 & 3.6 \\
\hline & Pregnant & 326 & 6.6 \\
\hline & Amenorrheic & 472 & 9.6 \\
\hline & Infecund, menopausal & 442 & 9.0 \\
\hline \multicolumn{2}{|c|}{ Never/formerly married } & 2040 & 41.5 \\
\hline \multicolumn{2}{|c|}{ Total } & 4916 & $\overline{100}$ \\
\hline
\end{tabular}

a 156 were using a traditional method, and 7 were not using any method but knowledge of a supply source was missing 
Table A.4: Distribution of unmet need for family planning and contraceptive use, fertility preferences

\begin{tabular}{|c|c|c|c|c|c|c|c|c|c|c|c|}
\hline & \multicolumn{2}{|c|}{ Total } & \multicolumn{2}{|c|}{ Residence } & \multicolumn{4}{|c|}{ Area } & \multicolumn{2}{|c|}{ Mother's age } \\
\hline & & $\begin{array}{l}\text { Weighted } \\
\mathrm{N}\end{array}$ & $\%$ & urban & rural & $\begin{array}{l}\text { Greater } \\
\text { Accra }\end{array}$ & $\begin{array}{c}\text { Southern } \\
\text { belt }\end{array}$ & Middle belt & Northern belt & $<30 \mathrm{yrs}$ & $30+y r s$ \\
\hline \multicolumn{12}{|c|}{ Percentages } \\
\hline \multirow{4}{*}{ 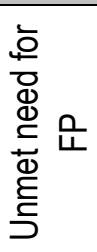 } & access \&attitude & 246 & 19.0 & 17.9 & 20.0 & 14.4 & 21.6 & 19.7 & 17.8 & 20.8 & 17.9 \\
\hline & access, but not attitude & 177 & 13.7 & 13.6 & 13.8 & 11.3 & 14.1 & 14.9 & 12.7 & 10.6 & 15.7 \\
\hline & attitude, but not access & 59 & 4.6 & 3.0 & 5.9 & 2.6 & 6.0 & 3.7 & 6.5 & 5.1 & 4.2 \\
\hline & $\begin{array}{l}\text { neither access nor } \\
\text { attitude }\end{array}$ & 67 & 5.2 & 3.5 & 6.7 & 2.8 & 9.5 & 3.2 & 5.4 & 5.7 & 4.9 \\
\hline \multirow{3}{*}{\multicolumn{2}{|c|}{$\begin{array}{l}\text { using to space } \\
\text { using to limit } \\
\text { desire birth }<2 \text { years }\end{array}$}} & 203 & 15.7 & 15.2 & 16.2 & 15.2 & 15.5 & 15.3 & 17.7 & 25.6 & 9.6 \\
\hline & & 207 & 16.0 & 18.0 & 14.3 & 25.2 & 15.4 & 15.4 & 8.5 & 4.3 & 23.3 \\
\hline & & 333 & 25.8 & 28.8 & 23.1 & 28.5 & 17.9 & 27.8 & 31.5 & 27.9 & 24.4 \\
\hline \multicolumn{2}{|l|}{ Total } & 1294 & 100.0 & 100 & 100 & 100 & 100 & 100 & 100 & 100 & 100 \\
\hline \multicolumn{2}{|c|}{ Total unmet need } & & 42.5 & 38.0 & 46.4 & 31.1 & 51.2 & 41.5 & 42.3 & 42.3 & 42.7 \\
\hline \multicolumn{2}{|c|}{$p$-value for $x^{2}$ test } & & & & 0.022 & & & & $<0.001$ & & $<0.001$ \\
\hline \multicolumn{12}{|c|}{ Weighted N } \\
\hline \multirow{4}{*}{ 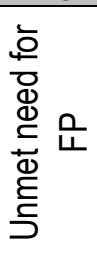 } & access \&attitude & 246 & 19.0 & 108 & 139 & 32 & 77 & 102 & 35 & 104 & 143 \\
\hline & access, but not attitude & 177 & 13.7 & 82 & 96 & 25 & 50 & 77 & 25 & 53 & 125 \\
\hline & attitude, but not access & 59 & 4.6 & 18 & 41 & 6 & 21 & 19 & 13 & 26 & 33 \\
\hline & $\begin{array}{l}\text { neither access nor } \\
\text { attitude }\end{array}$ & 67 & 5.2 & 21 & 47 & 6 & 34 & 17 & 11 & 29 & 39 \\
\hline \multirow{3}{*}{\multicolumn{2}{|c|}{$\begin{array}{l}\text { using to space } \\
\text { using to limit } \\
\text { desire birth <2 years }\end{array}$}} & 203 & 15.7 & 91 & 112 & 34 & 55 & 80 & 35 & 127 & 76 \\
\hline & & 207 & 16.0 & 108 & 99 & 56 & 55 & 80 & 17 & 21 & 186 \\
\hline & & 333 & 25.8 & 173 & 160 & 63 & 64 & 144 & 62 & 139 & 195 \\
\hline \multicolumn{2}{|l|}{ Total } & 1294 & 100.0 & 600 & 694 & 221 & 355 & 519 & 198 & 497 & 796 \\
\hline
\end{tabular}




\begin{tabular}{|c|c|c|c|c|c|c|c|c|c|c|}
\hline & & \multicolumn{4}{|c|}{ Mother's education } & \multicolumn{5}{|c|}{ Wealth } \\
\hline & & no education & primary & middle/JSS & secondary+ & poorest & poorer & middle & richer & richest \\
\hline \multicolumn{11}{|c|}{ Percentages } \\
\hline \multirow{4}{*}{ 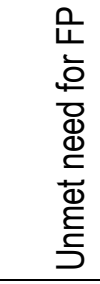 } & access \&attitude & 21.6 & 20.3 & 17.4 & 16.9 & 20.8 & 22.6 & 19.0 & 18.5 & 15.7 \\
\hline & access, but not attitude & 12.9 & 14.9 & 13.9 & 12.7 & 11.3 & 14.1 & 15.3 & 14.0 & 13.5 \\
\hline & attitude, but not access & 7.3 & 5.3 & 3.7 & 1.0 & 9.5 & 6.7 & 3.0 & 4.5 & 1.2 \\
\hline & $\begin{array}{l}\text { neither access nor } \\
\text { attitude }\end{array}$ & 11.1 & 3.9 & 4.2 & 0.0 & 9.3 & 6.3 & 6.7 & 4.4 & 1.4 \\
\hline \multirow{3}{*}{\multicolumn{2}{|c|}{$\begin{array}{l}\text { using to space } \\
\text { using to limit } \\
\text { desire birth }<2 \text { years }\end{array}$}} & 10.4 & 18.7 & 16.4 & 18.0 & 13.4 & 18.5 & 16.4 & 17.2 & 13.3 \\
\hline & & 13.0 & 14.2 & 19.6 & 14.2 & 12.1 & 11.5 & 15.6 & 17.3 & 21.0 \\
\hline & & 23.8 & 22.7 & 24.8 & 37.2 & 23.6 & 20.3 & 24.0 & 24.2 & 33.9 \\
\hline \multicolumn{2}{|c|}{ Total } & 100 & 100 & 100 & 100 & 100.0 & 100.0 & 100.0 & 100.0 & 100.0 \\
\hline \multicolumn{2}{|c|}{ Total unmet need } & 52.8 & 44.4 & 39.2 & 30.6 & 50.9 & 49.7 & 44.1 & 41.3 & 31.8 \\
\hline \multicolumn{2}{|c|}{$p$-value for $x^{2}$ test } & & & & $<0.001$ & & & & & $<0.001$ \\
\hline \multicolumn{11}{|c|}{ Weighted N } \\
\hline \multirow{4}{*}{ 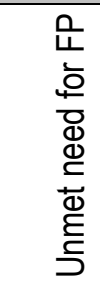 } & access \&attitude & 67 & 61 & 88 & 30 & 42 & 55 & 46 & 53 & 51 \\
\hline & access, but not attitude & 40 & 45 & 71 & 22 & 23 & 34 & 37 & 40 & 44 \\
\hline & attitude, but not access & 23 & 16 & 19 & 2 & 19 & 16 & 7 & 13 & 4 \\
\hline & $\begin{array}{l}\text { neither access nor } \\
\text { attitude }\end{array}$ & 34 & 12 & 21 & 0 & 19 & 15 & 16 & 12 & 5 \\
\hline \multicolumn{2}{|c|}{ using to space } & 32 & 56 & 83 & 32 & 27 & 45 & 40 & 49 & 43 \\
\hline \multirow{2}{*}{\multicolumn{2}{|c|}{$\begin{array}{l}\text { using to limit } \\
\text { desire birth }<2 \text { years }\end{array}$}} & 40 & 43 & 99 & 25 & 25 & 28 & 38 & 49 & 68 \\
\hline & & 74 & 68 & 126 & 65 & 48 & 49 & 58 & 69 & 110 \\
\hline \multicolumn{2}{|l|}{ Total } & 311 & 300 & 507 & 175 & 202 & 243 & 241 & 285 & 323 \\
\hline
\end{tabular}




\begin{tabular}{|c|c|c|c|c|c|c|c|c|c|c|c|}
\hline & \multicolumn{4}{|c|}{ Wealth \& Residence } & \multicolumn{6}{|c|}{ Mother's education + residence } \\
\hline & & $\begin{array}{l}\text { urban/ } \\
\text { poor }\end{array}$ & $\begin{array}{l}\text { urban/ } \\
\text { rich }\end{array}$ & $\begin{array}{l}\text { rural/ } \\
\text { poor }\end{array}$ & $\begin{array}{l}\text { rural/ } \\
\text { rich }\end{array}$ & $\begin{array}{l}\text { urban/no or } \\
\text { primary } \\
\text { education }\end{array}$ & $\begin{array}{l}\text { urban/middle or } \\
\text { JSS }\end{array}$ & urban/secondary+ & $\begin{array}{l}\text { rural/no } \\
\text { education }\end{array}$ & rural/primary & $\begin{array}{c}\text { rural/middle or } \\
\text { JSS+ }\end{array}$ \\
\hline \multicolumn{12}{|c|}{ Percentages } \\
\hline \multirow{4}{*}{ 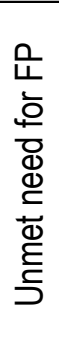 } & access \&attitude & 22.4 & 14.6 & 22.7 & 18.1 & 23.8 & 14.5 & 16.6 & 20.7 & 18.6 & 20.4 \\
\hline & $\begin{array}{l}\text { access, but not } \\
\text { attitude }\end{array}$ & 11.3 & 15.2 & 14.2 & 13.6 & 13.6 & 14.0 & 12.8 & 12.8 & 15.4 & 13.7 \\
\hline & $\begin{array}{l}\text { attitude, but not } \\
\text { access }\end{array}$ & 4.6 & 1.8 & 8.1 & 4.4 & 3.0 & 4.1 & 1.1 & 8.6 & 6.9 & 2.9 \\
\hline & $\begin{array}{l}\text { neither access nor } \\
\text { attitude }\end{array}$ & 6.4 & 1.3 & 7.5 & 6.2 & 6.1 & 3.5 & 0.0 & 12.8 & 2.7 & 4.4 \\
\hline \multirow{3}{*}{\multicolumn{2}{|c|}{$\begin{array}{l}\text { using to space } \\
\text { using to limit } \\
\text { desire birth }<2 \text { years }\end{array}$}} & 16.7 & 14.1 & 14.1 & 17.6 & 16.4 & 13.5 & 16.8 & 10.0 & 17.9 & 20.2 \\
\hline & & 12.1 & 22.3 & 11.8 & 16.0 & 13.2 & 22.4 & 15.9 & 14.1 & 13.3 & 15.2 \\
\hline & & 26.5 & 30.6 & 21.7 & 24.1 & 23.9 & 28.1 & 36.9 & 21.1 & 25.3 & 23.3 \\
\hline \multicolumn{2}{|c|}{ Total } & 100 & 100 & 100 & 100 & 100.0 & 100.0 & 100.0 & 100.0 & 100.0 & 100.0 \\
\hline \multicolumn{2}{|c|}{ Total unmet need } & 44.7 & 33.0 & 52.5 & 42.3 & 46.5 & 36.0 & 30.4 & 54.7 & 43.5 & 41.3 \\
\hline \multicolumn{2}{|c|}{$p$-value for $x^{2}$ test } & & & & $<0.001$ & & & & & & $<0.001$ \\
\hline
\end{tabular}

\section{Weighted N}

\begin{tabular}{|c|c|c|c|c|c|c|c|c|c|c|c|}
\hline \multirow{4}{*}{ 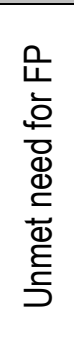 } & access \&attitude & 57 & 50 & 63 & 75 & 45 & 39 & 23 & 48 & 36 & 55 \\
\hline & $\begin{array}{l}\text { access, but not } \\
\text { attitude }\end{array}$ & 29 & 52 & 40 & 56 & 26 & 38 & 18 & 29 & 30 & 37 \\
\hline & $\begin{array}{l}\text { attitude, but not } \\
\text { access }\end{array}$ & 12 & 6 & 23 & 18 & 6 & 11 & 2 & 20 & 13 & 8 \\
\hline & $\begin{array}{l}\text { neither access nor } \\
\text { attitude }\end{array}$ & 16 & 5 & 21 & 26 & 11 & 9 & 0 & 29 & 5 & 12 \\
\hline \multicolumn{2}{|c|}{$\begin{array}{l}\text { using to space } \\
\text { using to limit } \\
\text { desire birth }<2 \text { years }\end{array}$} & 43 & 48 & 39 & 73 & 31 & 36 & 24 & 23 & 35 & 55 \\
\hline \multicolumn{2}{|c|}{ Total } & 256 & 344 & 280 & 414 & 188 & 271 & 141 & 230 & 193 & 270 \\
\hline
\end{tabular}




\begin{tabular}{|c|c|c|c|c|c|c|c|c|}
\hline & \multicolumn{3}{|c|}{ Postpartum } & \multicolumn{2}{|c|}{ Postpartum(last birth <2 yrs) } & \multicolumn{2}{|c|}{ Non-postpartum (last birth>=2 yrs) } \\
\hline & & $\begin{array}{c}\text { no } \\
\text { children }\end{array}$ & $\begin{array}{c}\text { had } \\
\text { birth in } \\
\text { the } \\
\text { past } 0 \text { - } \\
2 \text { yrs }\end{array}$ & $\begin{array}{c}\text { had a birth } \\
\text { in the past } \\
2+\text { yrs }\end{array}$ & $\begin{array}{l}\text { Not currently } \\
\text { breastfeeding }\end{array}$ & $\begin{array}{c}\text { Currently } \\
\text { breastfeeding }\end{array}$ & $\begin{array}{l}\text { Not currently } \\
\text { breastfeeding }\end{array}$ & $\begin{array}{c}\text { Currently } \\
\text { breastfeeding }\end{array}$ \\
\hline \multicolumn{9}{|c|}{ Percentages } \\
\hline \multirow{4}{*}{ 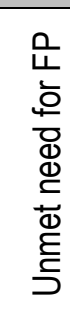 } & access \&attitude & 8.5 & 31.6 & 15.0 & 26.0 & 33.2 & 14.6 & 23.4 \\
\hline & access, but not attitude & 3.3 & 13.3 & 15.3 & 17.7 & 12.0 & 15.7 & 7.5 \\
\hline & attitude, but not access & 1.1 & 9.0 & 3.1 & 4.4 & 10.4 & 2.7 & 12.5 \\
\hline & neither access nor attitude & 4.4 & 5.7 & 5.1 & 2.6 & 6.6 & 5.0 & 8.8 \\
\hline \multirow{3}{*}{\multicolumn{2}{|c|}{$\begin{array}{l}\text { using to space } \\
\text { using to limit } \\
\text { desire birth }<2 \text { years }\end{array}$}} & 21.6 & 21.4 & 12.4 & 23.1 & 20.9 & 12.5 & 10.7 \\
\hline & & 0.0 & 13.4 & 19.4 & 11.7 & 13.8 & 19.8 & 9.8 \\
\hline & & 61.1 & 5.7 & 29.7 & 14.5 & 3.1 & 29.8 & 27.4 \\
\hline \multicolumn{2}{|c|}{ Total } & 100.0 & 100.0 & 100.0 & 100.0 & 100.0 & 100.0 & 100.0 \\
\hline \multicolumn{2}{|c|}{ Total unmet need } & 17.3 & 59.6 & 38.5 & 50.7 & 62.2 & 37.9 & 52.2 \\
\hline \multicolumn{2}{|c|}{$p$-value for $x^{2}$ test } & & & $<0.001$ & & 0.009 & & 0.01 \\
\hline \multicolumn{9}{|c|}{ Weighted N } \\
\hline \multirow{4}{*}{ 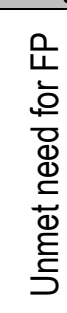 } & access \&attitude & 10 & 114 & 123 & 21 & 92 & 115 & 8 \\
\hline & access, but not attitude & 4 & 48 & 126 & 15 & 33 & 123 & 3 \\
\hline & attitude, but not access & 1 & 33 & 25 & 4 & 29 & 21 & 4 \\
\hline & neither access nor attitude & 5 & 21 & 42 & 2 & 18 & 39 & 3 \\
\hline \multirow{3}{*}{\multicolumn{2}{|c|}{$\begin{array}{l}\text { using to space } \\
\text { using to limit } \\
\text { desire birth }<2 \text { years }\end{array}$}} & 24 & 77 & 102 & 19 & 58 & 99 & 4 \\
\hline & & 0 & 48 & 159 & 10 & 38 & 156 & 3 \\
\hline & & 69 & 20 & 244 & 12 & 9 & 235 & 9 \\
\hline \multicolumn{2}{|c|}{ Total } & 112 & 360 & 822 & 82 & 278 & 788 & 33 \\
\hline
\end{tabular}




\begin{tabular}{|c|c|c|c|c|c|c|c|c|}
\hline & \multicolumn{3}{|c|}{ Parity } & \multicolumn{2}{|c|}{ Want another child } & \multicolumn{2}{|c|}{ Use of modern FP } \\
\hline & & $0-2$ children & $\begin{array}{c}3 \text { or } 4 \\
\text { children }\end{array}$ & $5+$ children & Yes & No & $\begin{array}{l}\text { Never used } \\
\text { modern FP }\end{array}$ & $\begin{array}{l}\text { Ever used } \\
\text { modern FP }\end{array}$ \\
\hline \multicolumn{9}{|c|}{ Percentages } \\
\hline \multirow{4}{*}{ 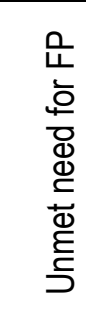 } & access \&attitude & 16.0 & 23.5 & 18.5 & 16.1 & 24.3 & 22.2 & 17.5 \\
\hline & access, but not attitude & 9.8 & 14.0 & 20.0 & 10.7 & 19.2 & 19.6 & 10.8 \\
\hline & attitude, but not access & 2.9 & 5.8 & 5.8 & 4.3 & 5.0 & 10.5 & 1.7 \\
\hline & neither access nor attitude & 4.9 & 3.9 & 7.4 & 4.7 & 6.2 & 12.3 & 1.8 \\
\hline \multirow{3}{*}{\multicolumn{2}{|c|}{$\begin{array}{l}\text { using to space } \\
\text { using to limit } \\
\text { desire birth }<2 \text { years }\end{array}$}} & 23.8 & 13.1 & 5.4 & 24.3 & 0.0 & 0.0 & 23.4 \\
\hline & & 2.9 & 22.3 & 30.2 & 0.0 & 45.4 & 0.0 & 23.8 \\
\hline & & 39.7 & 17.5 & 12.8 & 39.8 & 0.0 & 35.4 & 21.1 \\
\hline \multicolumn{2}{|c|}{ Total } & 100.0 & 100.0 & 100.0 & 100.0 & 100.0 & 100.0 & 100.0 \\
\hline \multicolumn{2}{|c|}{ Total unmet need } & 33.6 & 47.2 & 51.7 & 35.9 & 54.7 & 64.6 & 31.8 \\
\hline \multicolumn{2}{|c|}{$p$-value for $x^{2}$ test } & & & $<0.001$ & & $<0.001$ & & $<0.001$ \\
\hline \multicolumn{9}{|c|}{ Weighted N } \\
\hline \multirow{4}{*}{ 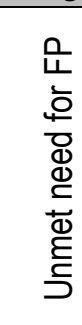 } & access \&attitude & 88 & 98 & 60 & 135 & 111 & 94 & 152 \\
\hline & access, but not attitude & 54 & 58 & 65 & 90 & 88 & 83 & 94 \\
\hline & attitude, but not access & 16 & 24 & 19 & 36 & 23 & 44 & 15 \\
\hline & neither access nor attitude & 27 & 16 & 24 & 39 & 28 & 52 & 15 \\
\hline \multirow{3}{*}{\multicolumn{2}{|c|}{$\begin{array}{l}\text { using to space } \\
\text { using to limit } \\
\text { desire birth }<2 \text { years }\end{array}$}} & 132 & 54 & 18 & 203 & 0 & 0 & 203 \\
\hline & & 16 & 93 & 98 & 0 & 207 & 0 & 207 \\
\hline & & 219 & 73 & 42 & 333 & 0 & 150 & 183 \\
\hline \multicolumn{2}{|c|}{ Total } & 552 & 415 & 326 & 837 & 457 & 424 & 870 \\
\hline
\end{tabular}




\begin{tabular}{|c|c|c|c|c|c|c|c|c|}
\hline & \multicolumn{7}{|c|}{ Religion } \\
\hline & & Catholic & Protestant & $\begin{array}{c}\text { Other } \\
\text { Christian }\end{array}$ & Moslem & Traditional & Others & Total \\
\hline \multicolumn{9}{|c|}{ Percentages } \\
\hline \multirow{4}{*}{ 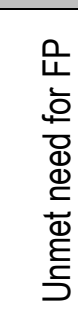 } & access \&attitude & 13.5 & 20.6 & 23.2 & 15.3 & 22.1 & 8.6 & 19.0 \\
\hline & access, but not attitude & 13.9 & 13.8 & 13.1 & 15.5 & 10.7 & 11.3 & 13.7 \\
\hline & attitude, but not access & 4.0 & 4.6 & 2.1 & 5.0 & 11.1 & 3.6 & 4.6 \\
\hline & neither access nor attitude & 4.8 & 4.0 & 6.5 & 7.0 & 13.3 & 3.7 & 5.2 \\
\hline \multirow{3}{*}{\multicolumn{2}{|c|}{$\begin{array}{l}\text { using to space } \\
\text { using to limit } \\
\text { desire birth }<2 \text { years }\end{array}$}} & 24.4 & 14.7 & 10.3 & 17.7 & 9.2 & 20.4 & 15.7 \\
\hline & & 12.6 & 18.9 & 17.1 & 6.3 & 12.4 & 19.5 & 16.0 \\
\hline & & 26.8 & 23.4 & 27.8 & 33.1 & 21.3 & 32.8 & 25.8 \\
\hline \multicolumn{2}{|c|}{ Total } & 100.0 & 100.0 & 100.0 & 100.0 & 100.0 & 100.0 & 100.0 \\
\hline \multicolumn{2}{|c|}{ Total unmet need } & 36.2 & 43.1 & 44.8 & 42.9 & 57.1 & 27.3 & 42.5 \\
\hline \multicolumn{2}{|c|}{$p$-value for $x^{2}$ test } & & & & & & & 0.0013 \\
\hline \multicolumn{9}{|c|}{ Weighted N } \\
\hline \multirow{4}{*}{ 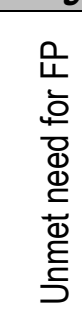 } & access \&attitude & 23 & 144 & 37 & 24 & 14 & 4 & 246 \\
\hline & access, but not attitude & 24 & 97 & 21 & 25 & 7 & 5 & 177 \\
\hline & attitude, but not access & 7 & 32 & 3 & 8 & 7 & 2 & 59 \\
\hline & neither access nor attitude & 8 & 28 & 10 & 11 & 8 & 2 & 67 \\
\hline \multicolumn{2}{|c|}{ using to space } & 42 & 103 & 16 & 28 & 6 & 9 & 203 \\
\hline \multirow{2}{*}{\multicolumn{2}{|c|}{$\begin{array}{l}\text { using to limit } \\
\text { desire birth <2 years }\end{array}$}} & 22 & 132 & 27 & 10 & 8 & 8 & 207 \\
\hline & & 46 & 163 & 44 & 53 & 13 & 14 & 333 \\
\hline \multicolumn{2}{|c|}{ Total } & 171 & 699 & 160 & 160 & 62 & 42 & 1294 \\
\hline
\end{tabular}


Table A.5: Logistic regression: Odds ratio of women having unmet need for family planning

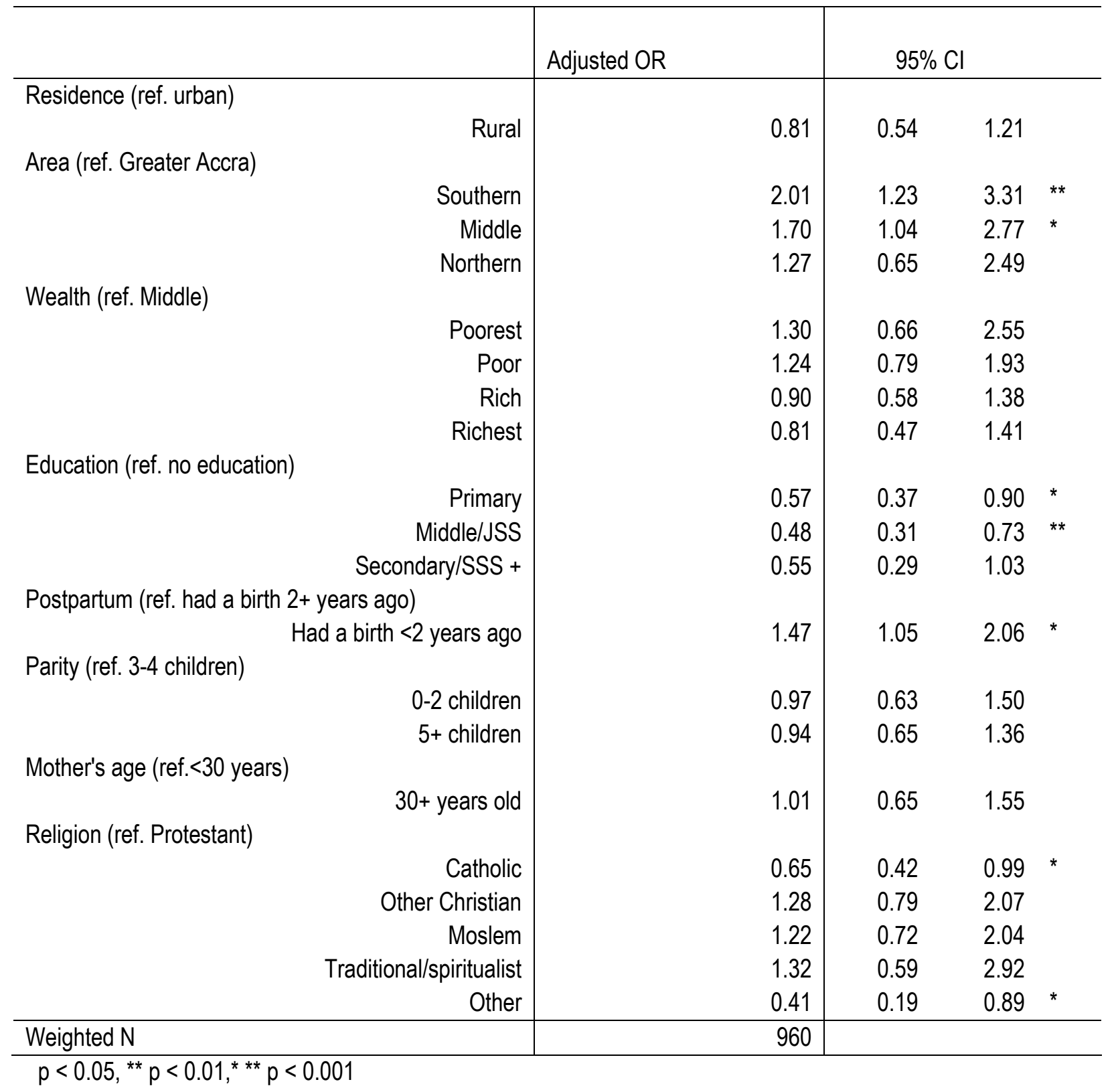




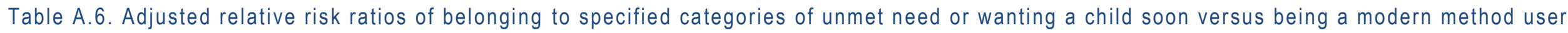

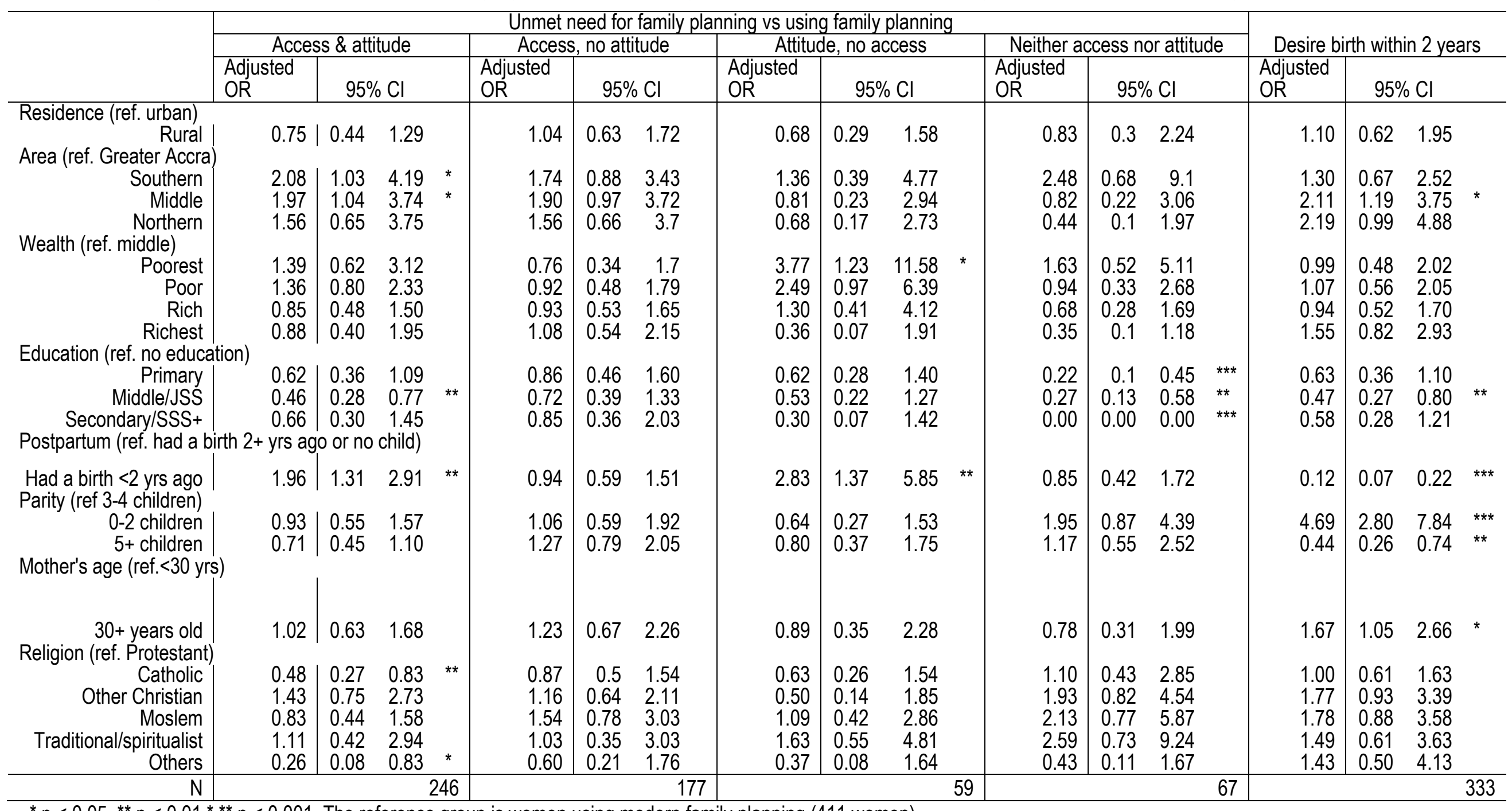

${ }^{*} p<0.05,{ }^{* *} p<0.01,{ }^{* * *} p<0.001$. The reference group is women using modern family planning (411 women). 
Table A.7: Number of reasons for non-use per woman

\begin{tabular}{ccccccc}
\hline & \multicolumn{5}{c}{ Unmet need for family planning } \\
\cline { 2 - 7 } No of reasons & $\begin{array}{c}\text { access \& } \\
\text { attitude }\end{array}$ & $\begin{array}{c}\text { access, but not } \\
\text { attitude }\end{array}$ & $\begin{array}{c}\text { attitude, but not } \\
\text { access }\end{array}$ & $\begin{array}{c}\text { neither access nor } \\
\text { attitude }\end{array}$ & Total \\
\hline & 0 & 12.1 & 11.4 & 14.2 & 18.8 & 12.9 \\
& 1 & 79.6 & 77.2 & 83.0 & 77.0 & 78.9 \\
& 2 & 8.2 & 11.3 & 2.8 & 4.2 & 8.1 \\
& 3 & 0.2 & 0.0 & 0.0 & 0.0 & 0.1 \\
\hline
\end{tabular}

Table A.8: Adjusted odds ratios for not having sex in the last 4 weeks versus having sex in the last 4 weeks

\begin{tabular}{|c|c|c|c|c|c|}
\hline & $\begin{array}{l}\text { Adjusted } \\
\text { OR }\end{array}$ & \multicolumn{3}{|c|}{$95 \% \mathrm{Cl}$} \\
\hline \multicolumn{6}{|c|}{ Fertility preference and preferred waiting time (ref. want a/another child soon, now) } \\
\hline \multirow{2}{*}{\multicolumn{2}{|c|}{$\begin{array}{r}\text { want no more child } \\
\text { undecided about having a/another child }\end{array}$}} & 2.04 & 1.26 & 3.30 & ** \\
\hline & & 1.66 & 0.83 & 3.29 & \\
\hline \multirow{5}{*}{ 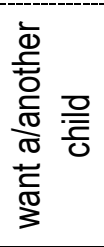 } & $<12$ months & 1.44 & 0.48 & 4.31 & \\
\hline & 1 year & 0.96 & 0.41 & 2.24 & \\
\hline & 2 years & 2.22 & 1.20 & 4.11 & * \\
\hline & $>=3 \mathrm{yrs}$ & 1.85 & 1.16 & 2.97 & * \\
\hline & do not know about the timing or reported non-numeric answer & 2.14 & 0.88 & 5.20 & \\
\hline \multicolumn{2}{|c|}{ Living arrangement (living with husband now) } & 4.40 & 3.22 & 6.02 & $* * *$ \\
\hline \multicolumn{2}{|c|}{ Using a modern method (ref. users) } & 2.13 & 1.54 & 2.94 & $* * *$ \\
\hline Reside & Rural & 0.72 & 0.54 & 0.98 & * \\
\hline \multicolumn{2}{|c|}{ Education (ref. no education) } & & & & \\
\hline & Primary & 0.95 & 0.64 & 1.41 & \\
\hline & Middle/JSS & 0.74 & 0.51 & 1.07 & \\
\hline & Secondary/SSS+ & 0.77 & 0.45 & 1.34 & \\
\hline \multicolumn{2}{|c|}{ Parity (ref. $0-2$ children) } & & & & \\
\hline & 3 or 4 children & 1.00 & 0.68 & 1.48 & \\
\hline & $5+$ children & 0.79 & 0.48 & 1.30 & \\
\hline \multicolumn{2}{|c|}{ Polygyny (ref. monogamous) } & & & & \\
\hline \multicolumn{2}{|c|}{ have co-wives } & 0.88 & 0.58 & 1.33 & \\
\hline \multicolumn{2}{|c|}{ Postpartum (ref. no child/birth 2+ yrs ago) } & & & & \\
\hline \multicolumn{2}{|r|}{ Had a birth in the past $2 \mathrm{yrs}$} & 1.07 & 0.75 & 1.53 & \\
\hline \multicolumn{2}{|c|}{ Age group $(<30$ years old $)$} & & & & \\
\hline & $>=30$ & 1.18 & 0.80 & 1.74 & \\
\hline & $\mathrm{N}$ & 1281 & & & \\
\hline
\end{tabular}




\section{www.stepup.popcouncil.org}

The STEP UP (Strengthening Evidence for Programming on Unintended Pregnancy) Research Programme Consortium generates policy-relevant research to promote an evidence-based approach for improving access to family planning and safe abortion. STEP UP focuses its activities in five countries: Bangladesh, Ghana, India, Kenya, and Senegal.

STEP UP is coordinated by the Population Council in partnership with the African Population and Health Research Center; icddr,b; the London School of Hygiene and Tropical Medicine; Marie Stopes International; and Partners in Population and Development. STEP UP is funded by UK aid from the UK Government. 